\title{
The demographic and evolutionary consequences of selective mortality: Predictions from an eco-genetic model of smallmouth bass
}

Erin S. Dunlop (dunlop@iiasa.ac.at)

Brian J. Shuter (shuter@zoo.utoronto.ca)

Ulf Dieckmann (dieckmann@iiasa.ac.at)

Approved by

Leen Hordijk

Director, IIASA

December 2006 


\section{IIASA STUDIES IN ADAPTIVE DYNAMICS No. 121}

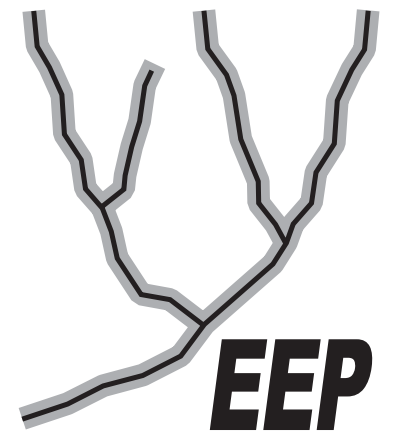

The Evolution and Ecology Program at IIASA fosters the development of new mathematical and conceptual techniques for understanding the evolution of complex adaptive systems.

Focusing on these long-term implications of adaptive processes in systems of limited growth, the Evolution and Ecology Program brings together scientists and institutions from around the world with IIASA acting as the central node.

Scientific progress within the network is collected in the IIASA Studies in Adaptive Dynamics series.
No. 1 Metz JAJ, Geritz SAH, Meszéna G, Jacobs FJA, van Heerwaarden JS: Adaptive Dynamics: A Geometrical Study of the Consequences of Nearly Faithful Reproduction. IIASA Working Paper WP-95-099 (1995). van Strien SJ, Verduyn Lunel SM (eds): Stochastic and Spatial Structures of Dynamical Systems, Proceedings of the Royal Dutch Academy of Science (KNAW Verhandelingen), North Holland, Amsterdam, pp. 183-231 (1996).

No. 2 Dieckmann U, Law R: The Dynamical Theory of Coevolution: A Derivation from Stochastic Ecological Processes. IIASA Working Paper WP-96-001 (1996). Journal of Mathematical Biology 34:579-612 (1996).

No. 3 Dieckmann U, Marrow P, Law R: Evolutionary Cycling of Predator-PreyInteractions: Population Dynamics and the Red Queen. IIASA Preprint (1995). Journal of Theoretical Biology 176:91-102 (1995).

No. 4 Marrow P, Dieckmann U, Law R: Evolutionary Dynamics of Predator-Prey Systems: An Ecological Perspective. IIASA Working Paper WP-96-002 (1996). Journal of Mathematical Biology 34:556-578 (1996).

No. 5 Law R, Marrow P, Dieckmann U: On Evolution under Asymmetric Competition. IIASA Working Paper WP-96-003 (1996). Evolutionary Ecology 11:485-501 (1997).

No. 6 Metz JAJ, Mylius SD, Diekmann O: When Does Evolution Optimize? On the Relation Between Types of Density Dependence and Evolutionarily Stable Life History Parameters. IIASA Working Paper WP-96-004 (1996).

No. 7 Ferrière R, Gatto M: Lyapunov Exponents and the Mathematics of Invasion in Oscillatory or Chaotic Populations. Theoretical Population Biology 48:126-171 (1995).

No. 8 Ferrière R, Fox GA: Chaos and Evolution. IIASA Preprint (1996). Trends in Ecology and Evolution 10:480485 (1995)

No. 9 Ferrière R, Michod RE: The Evolution of Cooperation in Spatially Heterogeneous Populations. IIASA Working Paper WP-96-029 (1996). The American Naturalist 147:692717 (1996)

No. 10 van Dooren TJM, Metz JAJ: Delayed Maturation in Temporally Structured Populations with Non-Equilibrium Dynamics. IIASA Working Paper WP-96-070 (1996). Journal of Evolutionary Biology 11:41-62 (1998).
No. 11 Geritz SAH, Metz JAJ, Kisdi É, Meszéna G: The Dynamics of Adaptation and Evolutionary Branching. IIASA Working Paper WP-96-077 (1996). Physical Review Letters 78:2024-2027 (1997).

No. 12 Geritz SAH, Kisdi É, Meszéna G, Metz JAJ: Evolutionary Singular Strategies and the Adaptive Growth and Branching of the Evolutionary Tree. IIASA Working Paper WP-96-114 (1996). Evolutionary Ecology 12:35-57 (1998).

No. 13 Heino M, Metz JAJ, Kaitala V: Evolution of Mixed Maturation Strategies in Semelparous Life-Histories: The Crucial Role of Dimensionality of Feedback Environment. IIASA Working Paper WP-96-126 (1996). Philosophical Transactions of the Royal Society of London Series B 352:1647-1655 (1997).

No. 14 Dieckmann U: Can Adaptive Dynamics Invade? IIASA Working Paper WP-96-152 (1996). Trends in Ecology and Evolution 12:128-131 (1997).

No. 15 Meszéna G, Czibula I, Geritz SAH: Adaptive Dynamics in a 2-Patch Environment: A Simple Model for Allopatric and Parapatric Speciation. IIASA Interim Report IR-97-001 (1997). Journal of Biological Systems 5:265-284 (1997).

No. 16 Heino M, Metz JAJ, Kaitala V: The Enigma of Frequency-Dependent Selection. IIASA Interim Report IR97-061 (1997). Trends in Ecology and Evolution 13:367-370 (1998).

No. 17 Heino M: Management of Evolving Fish Stocks. IIASA Interim Report IR-97-062 (1997). Canadian Journal of Fisheries and Aquatic Sciences 55:1971-1982 (1998).

No. 18 Heino M: Evolution of Mixed Reproductive Strategies in Simple Life-History Models. IIASA Interim Report IR-97063 (1997).

No. 19 Geritz SAH, van der Meijden E, Metz JAJ: Evolutionary Dynamics of Seed Size and Seedling Competitive Ability. IIASA Interim Report IR-97-071 (1997). Theoretical Population Biology 55:324-343 (1999).

No. 20 Galis F, Metz JAJ: Why Are There So Many Cichlid Species? On the Interplay of Speciation and Adaptive Radiation. IIASA Interim Report IR-97-072 (1997). Trends in Ecology and Evolution 13:1-2 (1998). 
No. 21 Boerlijst MC, Nowak MA, Sigmund K: Equal Pay for all Prisoners/ The Logic of Contrition. IIASA Interim Report IR-97-073 (1997). American Mathematical Society Monthly 104:303-307 (1997). Journal of Theoretical Biology 185:281-293 (1997).

No. 22 Law R, Dieckmann U: Symbiosis Without Mutualism and the Merger of Lineages in Evolution. IIASA Interim Report IR-97-074 (1997). Proceedings of the Royal Society of London Series B 265:1245-1253 (1998).

No. 23 Klinkhamer PGL, de Jong TJ, Metz JAJ: Sex and Size in Cosexual Plants. IIASA Interim Report IR-97-078 (1997). Trends in Ecology and Evolution 12:260-265 (1997).

No. 24 Fontana W, Schuster P: Shaping Space: The Possible and the Attainable in RNA Genotype-Phenotype Mapping. IIASA Interim Report IR-98-004 (1998). Journal of Theoretical Biology 194:491-515 (1998).

No. 25 Kisdi É, Geritz SAH: Adaptive Dynamics in Allele Space: Evolution of Genetic Polymorphism by Small Mutations in a Heterogeneous Environment. IIASA Interim Report IR-98-038 (1998). Evolution 53:993-1008 (1999).

No. 26 Fontana W, Schuster P: Continuity in Evolution: On the Nature of Transitions. IIASA Interim Report IR-98-039 (1998). Science 280:1451-1455 (1998).

No. 27 Nowak MA, Sigmund K: Evolution of Indirect Reciprocity by Image Scoring/ The Dynamics of Indirect Reciprocity. IIASA Interim Report IR-98-040 (1998). Nature 393:573-577 (1998). Journal of Theoretical Biology 194:561574 (1998).

No. 28 Kisdi É: Evolutionary Branching Under Asymmetric Competition. IIASA Interim Report IR-98-045 (1998). Journal of Theoretical Biology 197:149-162 (1999).

No. 29 Berger U: Best Response Adaptation for Role Games. IIASA Interim Report IR-98-086 (1998).

No. 30 van Dooren TJM: The Evolutionary Ecology of Dominance-Recessivity. IIASA Interim Report IR-98-096 (1998). Journal of Theoretical Biology 198:519-532 (1999).

No. 31 Dieckmann U, O'Hara B, Weisser W: The Evolutionary Ecology of Dispersal. IIASA Interim Report IR-98-108 (1998). Trends in Ecology and Evolution 14:88-90 (1999).

No. 32 Sigmund K: Complex Adaptive Systems and the Evolution of Reciprocation. IIASA Interim Report IR-98-100 (1998). Ecosystems 1:444-448 (1998).

No. 33 Posch M, Pichler A, Sigmund K: The Efficiency of Adapting Aspiration Levels. IIASA Interim Report IR-98103 (1998). Proceedings of the Royal Society London Series B 266:1427-1435 (1999).

No. 34 Mathias A, Kisdi É: Evolutionary Branching and Coexistence of Germination Strategies. IIASA Interim Report IR-99-014 (1999).

No. 35 Dieckmann U, Doebeli M: On the Origin of Species by Sympatric Speciation. IIASA Interim Report IR-99-013 (1999). Nature 400:354-357 (1999).

No. 36 Metz JAJ, Gyllenberg M: How Should We Define Fitness in Structured Metapopulation Models? Including an Application to the Calculation of Evolutionarily Stable Dispersal Strategies. IIASA Interim Report IR-99-019 (1999). Proceedings of the Royal Society of London Series B 268:499508 (2001)
No. 37 Gyllenberg M, Metz JAJ: On Fitness in Structured Metapopulations. IIASA Interim Report IR-99-037 (1999). Journal of Mathematical Biology 43:545-560 (2001).

No. 38 Meszéna G, Metz JAJ: Species Diversity and Population Regulation: The Importance of Environmental Feedback Dimensionality. IIASA Interim Report IR-99-045 (1999).

No. 39 Kisdi É, Geritz SAH: Evolutionary Branching and Sympatric Speciation in Diploid Populations. IIASA Interim Report IR-99-048 (1999).

No. 40 Ylikarjula J, Heino M, Dieckmann U: Ecology and Adaptation of Stunted Growth in Fish. IIASA Interim Report IR-99-050 (1999). Evolutionary Ecology 13:433-453 (1999).

No. 41 Nowak MA, Sigmund K: Games on Grids. IIASA Interim Report IR-99-038 (1999). Dieckmann U, Law R, Metz JAJ (eds): The Geometry of Ecological Interactions: Simplifying Spatial Complexity, Cambridge University Press, Cambridge, UK, pp. 135-150 (2000).

No. 42 Ferrière R, Michod RE: Wave Patterns in Spatial Games and the Evolution of Cooperation. IIASA Interim Report IR-99-041 (1999). Dieckmann U, Law R, Metz JAJ (eds): The Geometry of Ecological Interactions: Simplifying Spatial Complexity, Cambridge University Press, Cambridge, UK, pp. 318-332 (2000).

No. 43 Kisdi É, Jacobs FJA, Geritz SAH: Red Queen Evolution by Cycles of Evolutionary Branching and Extinction. IIASA Interim Report IR-00-030 (2000). Selection 2:161$176(2001)$.

No. 44 Meszéna G, Kisdi É, Dieckmann U, Geritz SAH, Metz JAJ: Evolutionary Optimisation Models and Matrix Games in the Unified Perspective of Adaptive Dynamics. IIASA Interim Report IR-00-039 (2000). Selection 2:193-210 (2001).

No. 45 Parvinen K, Dieckmann U, Gyllenberg M, Metz JAJ: Evolution of Dispersal in Metapopulations with Local Density Dependence and Demographic Stochasticity. IIASA Interim Report IR-00-035 (2000). Journal of Evolutionary Biology 16:143-153 (2003).

No. 46 Doebeli M, Dieckmann U: Evolutionary Branching and Sympatric Speciation Caused by Different Types of Ecological Interactions. IIASA Interim Report IR-00-040 (2000). The American Naturalist 156:S77-S101 (2000).

No. 47 Heino M, Hanski I: Evolution of Migration Rate in a Spatially Realistic Metapopulation Model. IIASA Interim Report IR-00-044 (2000). The American Naturalist 157:495$511(2001)$.

No. 48 Gyllenberg M, Parvinen K, Dieckmann U: Evolutionary Suicide and Evolution of Dispersal in Structured Metapopulations. IIASA Interim Report IR-00-056 (2000). Journal of Mathematical Biology 45:79-105 (2002).

No. 49 van Dooren TJM: The Evolutionary Dynamics of Direct Phenotypic Overdominance: Emergence Possible, Loss Probable. IIASA Interim Report IR-00-048 (2000). Evolution 54:1899-1914 (2000).

No. 50 Nowak MA, Page KM, Sigmund K: Fairness Versus Reason in the Ultimatum Game. IIASA Interim Report IR00-57 (2000). Science 289:1773-1775 (2000).

No. 51 de Feo O, Ferrière R: Bifurcation Analysis of Population Invasion: On-Off Intermittency and Basin Riddling. IIASA Interim Report IR-00-074 (2000). International Journal of Bifurcation and Chaos 10:443-452 (2000). 
No. 52 Heino M, Laaka-Lindberg S: Clonal Dynamics and Evolution of Dormancy in the Leafy Hepatic Lophozia Silvicola. IIASA Interim Report IR-01-018 (2001). Oikos 94:525-532 (2001).

No. 53 Sigmund K, Hauert C, Nowak MA: Reward and Punishment in Minigames. IIASA Interim Report IR-01-031 (2001). Proceedings of the National Academy of Sciences of the USA 98:10757-10762 (2001).

No. 54 Hauert C, De Monte S, Sigmund K, Hofbauer J: Oscillations in Optional Public Good Games. IIASA Interim Report IR-01-036 (2001).

No. 55 Ferrière R, Le Galliard J: Invasion Fitness and Adaptive Dynamics in Spatial Population Models. IIASA Interim Report IR-01-043 (2001). Clobert J, Dhondt A, Danchin E, Nichols J (eds): Dispersal, Oxford University Press, pp. 57-79 (2001).

No. 56 de Mazancourt C, Loreau M, Dieckmann U: Can the Evolution of Plant Defense Lead to Plant-Herbivore Mutualism? IIASA Interim Report IR-01-053 (2001). The American Naturalist 158:109-123 (2001).

No. 57 Claessen D, Dieckmann U: Ontogenetic Niche Shifts and Evolutionary Branching in Size-Structured Populations. IIASA Interim Report IR-01-056 (2001). Evolutionary Ecology Research 4:189-217 (2002).

No. 58 Brandt H: Correlation Analysis of Fitness Landscapes. IIASA Interim Report IR-01-058 (2001).

No. 59 Dieckmann U: Adaptive Dynamics of Pathogen-Host Interacations. IIASA Interim Report IR-02-007 (2002). Dieckmann U, Metz JAJ, Sabelis MW, Sigmund K (eds): Adaptive Dynamics of Infectious Diseases: In Pursuit of Virulence Management, Cambridge University Press, Cambridge, UK, pp. 39-59 (2002).

No. 60 Nowak MA, Sigmund K: Super- and Coinfection: The Two Extremes. IIASA Interim Report IR-02-008 (2002). Dieckmann U, Metz JAJ, Sabelis MW, Sigmund K (eds): Adaptive Dynamics of Infectious Diseases: In Pursuit of Virulence Management, Cambridge University Press, Cambridge, UK, pp. 124-137 (2002).

No. 61 Sabelis MW, Metz JAJ: Evolution Management: Taking Stock - Relating Theory to Experiment. IIASA Interim Report IR-02-009 (2002). Dieckmann U, Metz JAJ, Sabelis MW, Sigmund K (eds): Adaptive Dynamics of Infectious Diseases: In Pursuit of Virulence Management, Cambridge University Press, Cambridge, UK, pp. 379-398 (2002).

No. 62 Cheptou P, Dieckmann U: The Evolution of SelfFertilization in Density-Regulated Populations . IIASA Interim Report IR-02-024 (2002). Proceedings of the Royal Society of London Series B 269:1177-1186(2002).

No. 63 Bürger R: Additive Genetic Variation Under Intraspecific Competition and Stabilizing Selection: A Two-Locus Study. IIASA Interim Report IR-02-013 (2002). Theoretical Population Biology 61:197-213 (2002).

No. 64 Hauert C, De Monte S, Hofbauer J, Sigmund K: Volunteering as Red Queen Mechanism for Co-operation in Public Goods Games. IIASA Interim Report IR-02-041 (2002). Science 296:1129-1132 (2002).

No. 65 Dercole F, Ferrière R, Rinaldi S: Ecological Bistability and Evolutionary Reversals under Asymmetrical Competition. IIASA Interim Report IR-02-053 (2002). Evolution 56:1081-1090 (2002).
No. 66 Dercole F, Rinaldi S: Evolution of Cannibalistic Traits: Scenarios Derived from Adaptive Dynamics. IIASA Interim Report IR-02-054 (2002). Theoretical Population Biology 62:365-374 (2002).

No. 67 Bürger R, Gimelfarb A: Fluctuating Environments and the Role of Mutation in Maintaining Quantitative Genetic Variation. IIASA Interim Report IR-02-058 (2002). Genetical Research 80:31-46 (2002).

No. 68 Bürger R: On a Genetic Model of Intraspecific Competition and Stabilizing Selection. IIASA Interim Report IR02-062 (2002). Amer. Natur. 160:661-682 (2002).

No. 69 Doebeli M, Dieckmann U: Speciation Along Environmental Gradients. IIASA Interim Report IR-02-079 (2002). Nature 421:259-264 (2003).

No. 70 Dercole F, Irisson J, Rinaldi S: Bifurcation Analysis of a Prey-Predator Coevolution Model. IIASA Interim Report IR-02-078 (2002). SIAM Journal on Applied Mathematics 63:1378-1391 (2003).

No. 71 Le Galliard J, Ferrière R, Dieckmann U: The Adaptive Dynamics of Altruism in Spatially Heterogeneous Populations. IIASA Interim Report IR-03-006 (2003). Evolution 57:1-17 (2003).

No. 72 Taborsky B, Dieckmann U, Heino M: Unexpected Discontinuities in Life-History Evolution under SizeDependent Mortality. IIASA Interim Report IR-03-004 (2003). Proceedings of the Royal Society of London Series B 270:713-721 (2003).

No. 73 Gardmark A, Dieckmann U, Lundberg P: LifeHistory Evolution in Harvested Populations: The Role of Natural Predation. IIASA Interim Report IR-03-008 (2003). Evolutionary Ecology Research 5:239-257 (2003).

No. 74 Mizera F, Meszéna G: Spatial Niche Packing, Character Displacement and Adaptive Speciation Along an Environmental Gradient. IIASA Interim Report IR-03-062 (2003). Evolutionary Ecology Research 5:363-382 (2003).

No. 75 Dercole F: Remarks on Branching-Extinction Evolutionary Cycles. IIASA Interim Report IR-03-077 (2003). Journal of Mathematical Biology 47:569-580 (2003).

No. 76 Hofbauer J, Sigmund K: Evolutionary Game Dynamics. IIASA Interim Report IR-03-078 (2003). Bulletin of the American Mathematical Society 40:479-519 (2003).

No. 77 Ernande B, Dieckmann U, Heino M: Adaptive Changes in Harvested Populations: Plasticity and Evolution of Age and Size at Maturation. IIASA Interim Report IR03-058 (2003). Proceedings of the Royal Society of London Series B-Biological Sciences 271:415-423 (2004).

No. 78 Hanski I, Heino M: Metapopulation-Level Adaptation of Insect Host Plant Preference and Extinction-Colonization Dynamics in Heterogeneous Landscapes. IIASA Interim Report IR-03-028 (2003). Theoretical Population Biology 63:309-338 (2003).

No. 79 van Doorn G, Dieckmann U, Weissing FJ: Sympatric Speciation by Sexual Selection: A Critical Re-Evaluation. IIASA Interim Report IR-04-003 (2004). American Naturalist 163:709-725 (2004).

No. 80 Egas M, Dieckmann U, Sabelis MW: Evolution Restricts the Coexistence of Specialists and Generalists - the Role of Trade-off Structure. IIASA Interim Report IR-04-004 (2004). American Naturalist 163:518-531 (2004). 
No. 81 Ernande B, Dieckmann U: The Evolution of Phenotypic Plasticity in Spatially Structured Environments: Implications of Intraspecific Competition, Plasticity Costs, and Environmental Characteristics. IIASA Interim Report IR-04-006 (2004). Journal of Evolutionary Biology 17:613-628 (2004).

No. 82 Cressman R, Hofbauer J: Measure Dynamics on a One-Dimensional Continuous Trait Space: Theoretical Foundations for Adaptive Dynamics. IIASA Interim Report IR04-016 (2004).

No. 83 Cressman R: Dynamic Stability of the Replicator Equation with Continuous Strategy Space. IIASA Interim Report IR-04-017 (2004).

No. 84 Ravigné V, Olivieri I, Dieckmann U: Implications of Habitat Choice for Protected Polymorphisms. IIASA Interim Report IR-04-005 (2004). Evolutionary Ecology Research 6:125-145 (2004).

No. 85 Nowak MA, Sigmund K: Evolutionary Dynamics of Biological Games. IIASA Interim Report IR-04-013 (2004). Science 303:793-799 (2004).

No. 86 Vukics A, Asbóth J, Meszéna G: Speciation in Multidimensional Evolutionary Space. IIASA Interim Report IR-04-028 (2004). Physical Review 68:041-903 (2003).

No. 87 de Mazancourt C, Dieckmann U: Trade-off Geometries and Frequency-dependent Selection. IIASA Interim Report IR-04-039 (2004). American Naturalist 164:765-778 (2004).

No. 88 Cadet CR, Metz JAJ, Klinkhamer PGL: Size and the Not-So-Single Sex: Disentangling the Effects of Size on Sex Allocation. IIASA Interim Report IR-04-084 (2004). American Naturalist 164:779-792 (2004).

No. 89 Rueffler C, van Dooren TJM, Metz JAJ: Adaptive Walks on Changing Landscapes: Levins' Approach Extended. IIASA Interim Report IR-04-083 (2004). Theoretical Population Biology 65:165-178 (2004).

No. 90 de Mazancourt C, Loreau M, Dieckmann U: Understanding Mutualism When There is Adaptation to the Partner. IIASA Interim Report IR-05-016 (2005). Journal of Ecology 93:305-314 (2005).

No. 91 Dieckmann U, Doebeli M: Pluralism in Evolutionary Theory. IIASA Interim Report IR-05-017 (2005). Journal of Evolutionary Biology 18:1209-1213 (2005).

No. 92 Doebeli M, Dieckmann U, Metz JAJ, Tautz D: What We Have Also Learned: Adaptive Speciation is Theoretically Plausible. IIASA Interim Report IR-05-018 (2005). Evolution 59:691-695 (2005).

No. 93 Egas M, Sabelis MW, Dieckmann U: Evolution of Specialization and Ecological Character Displacement of Herbivores Along a Gradient of Plant Quality. IIASA Interim Report IR-05-019 (2005). Evolution 59:507-520 (2005).

No. 94 Le Galliard J, Ferrière R, Dieckmann U: Adaptive Evolution of Social Traits: Origin, Trajectories, and Correlations of Altruism and Mobility. IIASA Interim Report IR05-020 (2005). American Naturalist 165:206-224 (2005).

No. 95 Doebeli M, Dieckmann U: Adaptive Dynamics as a Mathematical Tool for Studying the Ecology of Speciation Processes. IIASA Interim Report IR-05-022 (2005). Journal of Evolutionary Biology 18:1194-1200 (2005).

No. 96 Brandt H, Sigmund K: The Logic of Reprobation: Assessment and Action Rules for Indirect Reciprocity. IIASA Interim Report IR-04-085 (2004). Journal of Theoretical Biology 231:475-486 (2004).
No. 97 Hauert C, Haiden N, Sigmund K: The Dynamics of Public Goods. IIASA Interim Report IR-04-086 (2004). Discrete and Continuous Dynamical Systems - Series B 4:575587 (2004).

No. 98 Meszéna G, Gyllenberg M, Jacobs FJA, Metz JAJ: Link Between Population Dynamics and Dynamics of Darwinian Evolution. IIASA Interim Report IR-05-026 (2005). Physical Review Letters 95:Article 078105 (2005).

No. 99 Meszéna G: Adaptive Dynamics: The Continuity Argument. IIASA Interim Report IR-05-032 (2005).

No. 100 Brännström NA, Dieckmann U: Evolutionary Dynamics of Altruism and Cheating Among Social Amoebas. IIASA Interim Report IR-05-039 (2005). Proceedings of the Royal Society London Series B 272:1609-1616 (2005).

No. 101 Meszéna G, Gyllenberg M, Pasztor L, Metz JAJ: Competitive Exclusion and Limiting Similarity: A Unified Theory. IIASA Interim Report IR-05-040 (2005).

No. 102 Szabo P, Meszéna G: Limiting Similarity Revisited. IIASA Interim Report IR-05-050 (2005).

No. 103 Krakauer DC, Sasaki A: The Greater than Two-Fold Cost of Integration for Retroviruses. IIASA Interim Report IR-05-069 (2005).

No. 104 Metz JAJ: Eight Personal Rules for Doing Science. IIASA Interim Report IR-05-073 (2005). Journal of Evolutionary Biology 18:1178-1181 (2005).

No. 105 Beltman JB, Metz JAJ: Speciation: More Likely Through a Genetic or Through a Learned Habitat Preference? IIASA Interim Report IR-05-072 (2005). Proceedings of the Royal Society of London Series B 272:1455-1463 (2005).

No. 106 Durinx M, Metz JAJ: Multi-type Branching Processes and Adaptive Dynamics of Structured Populations. IIASA Interim Report IR-05-074 (2005). Haccou P, Jager P, Vatutin V (eds): Branching Processes: Variation, Growth and Extinction of Populations, Cambridge University Press, Cambridge, UK, pp. 266-278 (2005).

No. 107 Brandt H, Sigmund K: The Good, the Bad and the Discriminator - Errors in Direct and Indirect Reciprocity. IIASA Interim Report IR-05-070 (2005). Journal of Theoretical Biology 239:183-194 (2006).

No. 108 Brandt H, Hauert C, Sigmund K: Punishing and Abstaining for Public Goods. IIASA Interim Report IR-05-071 (2005). Proceedings of the National Academy of Sciences of the United States of America 103:495-497 (2006).

No. 109 Ohtsuki A, Sasaki A: Epidemiology and DiseaseControl Under Gene-for-Gene Plant-Pathogen Interaction. IIASA Interim Report IR-05-068 (2005).

No. 110 Brandt H, Sigmund K: Indirect Reciprocity, ImageScoring, and Moral Hazard. IIASA Interim Report IR-05078 (2005). Proceedings of the National Academy of Sciences of the United States of America 102:2666-2670 (2005).

No. 111 Nowak MA, Sigmund K: Evolution of Indirect Reciprocity. IIASA Interim Report IR-05-079 (2005). Nature 437:1292-1298 (2005).

No. 112 Kamo M, Sasaki A: Evolution Towards Multi-Year Periodicity in Epidemics. IIASA Interim Report IR-05-080 (2005). Ecology Letters 8:378-385 (2005). 
No. 113 Dercole F, Ferrière R, Gragnani A, Rinaldi S: Coevolution of Slow-fast Populations: Evolutionary Sliding, Evolutionoary Pseudo-equilibria, and Complex Red Queen Dynamics. IIASA Interim Report IR-06-006 (2006). Proceedings of the Royal Society B-Biological Sciences 273:983-990 (2006).

No. 114 Dercole F: Border Collision Bifurcations in the Evolution of Mutualistic Interactions. IIASA Interim Report IR-05-083 (2005). International Journal of Bifurcation and Chaos 15:2179-2190 (2005).

No. 115 Dieckmann U, Heino M, Parvinen K: The Adaptive Dynamics of Function-Valued Traits. IIASA Interim Report IR-06-036 (2006). Journal of Theoretical Biology 241:370389 (2006).

No. 116 Dieckmann U, Metz JAJ: Surprising Evolutionary Predictions from Enhanced Ecological Realism. IIASA Interim Report IR-06-037 (2006). Theoretical Population Biology 69:263-281 (2006).

No. 117 Dieckmann U, Brännström NA, HilleRisLambers R, Ito $\mathrm{H}$ : The Adaptive Dynamics of Community Structure.
IIASA Interim Report IR-06-038 (2006). Takeuchi Y, Iwasa Y, Sato K (eds): Mathematics for Ecology and Environmental Sciences, Springer, Berlin Heidelberg, pp. 145-177 (2007).

No. 118 Gardmark A, Dieckmann U: Disparate Maturation Adaptations to Size-dependent Mortality. IIASA Interim Report IR-06-039 (2006). Proceedings of the Royal Society London Series B 273:2185-2192 (2006).

No. 119 van Doorn G, Dieckmann U: The Long-term Evolution of Multi-locus Traits Under Frequency-dependent Disruptive Selection. IIASA Interim Report IR-06-041 (2006). Evolution 60:2226-2238 (2006).

No. 120 Doebeli M, Blok HJ, Leimar O, Dieckmann U: Multimodal Pattern Formation in Phenotype Distributions of Sexual Populations. IIASA Interim Report IR-06-046 (2006). Proceedings of the Royal Society London Series B 274:347357 (2007)

No. 121 Dunlop ES, Shuter BJ, Dieckmann U: The Demographic and Evolutionary Consequences of Selective Mortality: Predictions from an Eco-genetic Model of the Smallmouth Bass. IIASA Interim Report IR-06-060 (2006).

Issues of the IIASA Studies in Adaptive Dynamics series can be obtained at www.iiasa.ac.at/Research/EEP/Series.html or by writing to eep@iiasa.ac.at. 


\section{Contents}

Introduction 
Running head: Mortality-induced evolution in the smallmouth bass

\title{
The demographic and evolutionary consequences of selective mortality: Predictions from an eco-genetic model of the smallmouth bass
}

\author{
Erin S. Dunlop ${ }^{1}$
}

Evolution and Ecology Program, International Institute for Applied Systems Analysis, A-2361

Laxenburg, Austria

Brian J. Shuter

Department of Zoology, University of Toronto, Toronto, Ontario, M5S 3G5, Canada and Harkness Laboratory of Fisheries Research, Aquatic Research and Development Section, Ontario Ministry of Natural Resources, 300 Water Street, Peterborough, Ontario K9J 8M5, Canada

\section{Ulf Dieckmann}

Evolution and Ecology Program, International Institute for Applied Systems Analysis, A-2361 Laxenburg, Austria

\footnotetext{
${ }^{1}$ Present address: Institute of Marine Research, P.O. Box 1870 Nordnes, N-5817 Bergen, Norway; email: erin.dunlop@imr.no
} 
Erin S. Dunlop, Brian J. Shuter, Ulf Dieckmann

\section{Abstract}

We use an individual-based eco-genetic model to examine the demographic and evolutionary consequences of selective mortality on a species with parental care, the smallmouth bass Micropterus dolomieu. Our analyses are grounded in a long-term (1936-2003) empirical study of the dynamics of two populations that differ widely in both density and life history. The model we construct extends previous approaches by including phenotypic plasticity in the age and size at maturation, by permitting density-dependent somatic growth, and by analyzing how costs associated with parental care alter model predictions. We show that, first, additional mortality on age- 0 individuals applied for 100 years causes reduced population abundance and biomass, faster somatic growth rates, and phenotypic plasticity toward slightly larger sizes at maturation. Second, mortality on individuals above a minimum size limit, also applied for 100 years, has a small influence on population abundance and somatic growth, causes a reduction of biomass, as well as substantial evolution of the probabilistic maturation reaction norm leading to younger ages and smaller sizes at maturation. Third, the incorporation of body-size-dependent survival costs associated with parental care (i.e., by reducing the number of small breeding adults at high population densities, increasing the mortality of parents that breed at small body sizes, or increasing the mortality of offspring originating from small-sized parents), reduces the amount of evolution predicted to occur within 100 years. Together, these results underscore that selective harvest can cause both phenotypically plastic responses and rapid evolution, however, the rate and magnitude of the evolved changes are sensitive to a species' life history characteristics.

Keywords: probabilistic maturation reaction norm; harvest; evolution; phenotypic plasticity; life history; density-dependent growth; eco-genetic model; fishing-induced adaptive change; parental care; individual-based model; species introduction. 
Erin S. Dunlop, Brian J. Shuter, Ulf Dieckmann

\section{Introduction}

To understand the effects of selective mortality on a population, it is critical to distinguish between plastic and evolutionary responses in key life history traits such as age and size at maturation (Reznick 1993; Rijnsdorp 1993). Selective mortality can induce rapid evolutionary changes in age and/or size at maturation (e.g., Reznick et al. 1990; Haugen and Vøllestad 2001) by favoring those individuals that reach maturity while minimizing their exposure to mortality (Law 2000). Selective mortality can also cause a phenotypically plastic response in age and size at maturation by altering environmental conditions for somatic growth through effects on population density and food availability (Law 2000; Hutchings 2004; Reznick and Ghalambor 2005; Dunlop et al. 2005b). Disentangling genetic and plastic responses is of particular significance to resource managers because genetic responses might take much longer to reverse than mere plastic changes (Law 2000). In the wild, however, it can be difficult to rule out the influence of confounding variables and to collect the data necessary for distinguishing between plastic and genetic responses. Models are therefore indispensable for predicting and understanding the consequences of selective mortality because they enable full control of any extraneous variables and salient assumptions.

In this study, we develop and analyze a model of mortality-induced evolution and parameterize it for a species with parental care, the smallmouth bass Micropterus dolomieu. We take a step beyond previous models of mortality-induced evolution (e.g., Law 1979; Abrams and Rowe 1996; Heino 1998; Martinez-Garmendia 1998; Ratner and Lande 2001) by permitting phenotypic plasticity in both the age and size at maturation, by allowing somatic growth to be density-dependent, and by including costs associated with parental care. This approach permits a more realistic framework in which to predict both the rate of evolutionary change and its 
Erin S. Dunlop, Brian J. Shuter, Ulf Dieckmann

endpoint. We include phenotypic plasticity in our study by modeling maturation reaction norms (MRNs). A MRN predicts the phenotypically plastic response of age and size at maturation to environmental variation in somatic growth rate (e.g., Stearns and Koella 1986; Roff 1992;

Ernande et al. 2004). Plastic changes in response to environmental variation in somatic growth will cause the realized combination of age and size at maturation to be shifted along the MRN, whereas selection is expected to force an evolutionary shift of the entire MRN away from its original position (Heino et al. 2002). Using this approach, studies of maturation in several marine fish stocks have demonstrated consistent correlations between high levels of harvest mortality and shifts in MRN position (Grift et al. 2003; Barot et al. 2004b; Olsen et al. 2004, 2005).

Despite the growing number of studies examining fishing-induced evolution (e.g., Baskett et al. 2005; Olsen et al. 2005; Reznick and Ghalambor 2005), it is not fully known how a species' life history characteristics influence the rate of the evolutionary response to selective mortality. Parental care is one important aspect of life history that is present in numerous fish species (Mank et al. 2005) and yet its influence on the response to selective mortality has received little, if any, attention. While parental care can improve offspring survival, such care can obviously be costly, by demanding a large expenditure of energy and by increasing a parent's exposure to predators (Clutton-Brock 1991). If sufficiently severe, these costs imply selective forces that might alter a population's predicted evolutionary response to mortality.

The focal species of our study, the smallmouth bass, shows paternal care in the form of an extended nest-guarding period that can last up to six weeks in the spring, during which the male parent fans the eggs to prevent fungal infection and defends the brood from potential predators (Ridgway 1988, 1989). The male feeds at a much diminished rate during the nest-guarding period (Ridgway and Shuter 1994), relying on stored energy reserves for sustenance (Mackereth et al. 1999). Evidence suggests that the presence of parental care in smallmouth bass is altering 
Erin S. Dunlop, Brian J. Shuter, Ulf Dieckmann

the selective forces acting on parental body size through three mechanisms. First, small males are disadvantaged because they emerge from winter with proportionately lower weight-specific energy reserves than larger males (Mackereth et al. 1999) and experience higher weight-specific maintenance costs (Shuter and Post 1990). Consequently, small males possess insufficient energy reserves for maintaining adult home ranges and for nest guarding when population density is high and food availability low (Ridgway et al. 2002). Therefore, small males might not initiate spawning even when they are mature, which could explain why the fraction of mature males that form a nest decreases with increasing population density (Ridgway et al. 2002). Second, smaller males might suffer higher over-winter mortality because their reserves are further depleted after the energetically demanding nest-guarding period (Shuter et al. 1980; Mackereth et al. 1999). Third, smaller males might be less effective at protecting their brood from predators and, accordingly, their offspring might suffer higher mortality (Ridgway and Friesen 1992; Wiegmann and Baylis 1995; Knotek and Orth 1998). The selective pressures resulting from the above three mechanisms favor the evolution of larger body sizes at maturation and might thus directly oppose those resulting from size-selective mortality on larger individuals, which, if acting alone, would favor maturation at smaller body sizes.

Two well-studied populations of smallmouth bass provide the empirical basis for assessing the usefulness of our modeling approach. The two study populations, one from Provoking Lake and the other from Opeongo Lake (Algonquin Provincial Park, Canada, $45^{\circ} 42^{\text {’N, }}$ $\left.78^{\circ} 22^{\prime} \mathrm{W}\right)$, were introduced from a common source in the early 1900 s. The Opeongo Lake population has been studied continuously since 1936 and the Provoking Lake population has been studied periodically from the late 1940s. Since their original introduction, these two populations have diverged, with Provoking Lake now supporting a population with a higher density, slower somatic growth rates, and smaller sizes at maturation relative to the Opeongo Lake population 
Erin S. Dunlop, Brian J. Shuter, Ulf Dieckmann

(Dunlop et al. 2005a). Empirical evidence suggests that the lower rates of predation on age-0 smallmouth bass in Provoking Lake, resulting from the depauperate fish community, might have contributed to the higher population density and slower somatic growth rates in that population (Dunlop et al. 2005a). Empirical evidence also indicates that, despite the existence of higher levels of mortality on the large size classes in Provoking Lake (Dunlop et al. 2005a), the two populations exhibit similar maturation reaction norms (Dunlop et al. 2005b). We will use our model to assess how the costs of parental care might be affecting the rates of maturation reaction norm evolution in these populations and whether it is reasonable to expect detectable changes in the maturation reaction norm after only 100 years of life in the different selective environments of Provoking Lake and Opeongo Lake.

In this study, we introduce an individual-based model that aims at incorporating the salient ecological processes underlying mortality-induced evolution. Throughout this study, we use the term 'eco-genetic' to characterize this model because it predicts the rates at which quantitative genetic traits evolve while at the same time integrating key aspects of the ecological setting (e.g., age and size structure, density-dependent growth, and phenotypic plasticity) into the selective environment that determines those rates. On this basis, we model the introduction of a smallmouth bass population into environments with differing levels of age- 0 mortality or sizeselective mortality and observe the implications of these differences for population dynamics, somatic growth, and maturation reaction norm evolution. We then incorporate the three possible body-size-related effects of parental care discussed above and determine how these additions alter predicted changes in demography and predicted rates of maturation reaction norm evolution. The detailed empirical data available for the Provoking Lake and Opeongo Lake populations provide a realistic context in which to evaluate these predictions and assess the possible role of parental care in determining how these populations have diverged since their introduction. 
Erin S. Dunlop, Brian J. Shuter, Ulf Dieckmann

\section{Methods}

An individual-based eco-genetic model was constructed to study the introduction of a smallmouth bass population into an environment with selective mortality. In accordance with the historical timeframe of the smallmouth bass introductions into Opeongo Lake and Provoking Lake, the eco-genetic model described below was run for 100 years in discrete, one-year time steps.

\section{Data sources}

Data from the Provoking Lake and Opeongo Lake smallmouth bass populations were used to parameterize the model. Empirical data have been collected on the Opeongo Lake population since its introduction in the early 1900s via an access point creel survey (Shuter et al. 1987). These creel data include temporal estimates of growth, population density, and mortality, corrected for changes in survey effectiveness (Shuter et al. 1987; Shuter and Ridgway 2002). Data also came from a multi-year spawning study conducted on Opeongo Lake from the 1980s to the present, as well as from detailed studies of growth and maturation conducted in 1981-1982 and 2000-2003 on Provoking and Opeongo Lakes (Ridgway et al. 1991; Dunlop et al. 2005a, b). The empirical relationships used to parameterize the model are depicted in Figure 1 and detailed parameter values are provided in Appendix 1.

\section{Probabilistic maturation reaction norms}

To account for the inherent stochasticity in the maturation process (Bernardo 1993), Heino et al. (2002) introduced the probabilistic maturation reaction norm (PMRN), defined as the probability of an individual to mature during the next season as a function of its current size and age. The midpoint of such a PMRN is defined as the size, separately for each age, at which the 
Erin S. Dunlop, Brian J. Shuter, Ulf Dieckmann

probability of maturing is $50 \%$ (Figure 1). The probabilistic envelope around the midpoint is given by the contour lines of equal maturation probability, ranging from just over 0 to just under $100 \%$ probability of maturation (Figure 1). The envelope's width is defined as the size interval, separately for each age, within which the probability of maturation rises from, say, $1 \%$ to $99 \%$. This PMRN approach has been used in recent studies to isolate the influence of growth on maturation (Dunlop et al. 2005b) and to reveal shifts in PMRNs suggestive of evolutionary responses to selective harvest (Grift et al. 2003; Barot et al. 2004b; Olsen et al. 2004, 2005). In our model, we consider a linear PMRN, with an evolving midpoint slope and intercept, and a constant width among ages. We model linear reaction norms (de Jong 1990) to reduce model complexity and we consider the slope and intercept of the reaction norm as separate evolving traits because they experience different selective pressures (e.g., Brommer et al. 2005).

\section{Genetic structure}

We use quantitative genetics principles (Falconer and Mackay 1996) to model the underlying genetic component of our populations. We assume that phenotypic plasticity (in maturation) is heritable by modeling genetically-based reaction norms that are passed from parents to offspring (e.g., Brommer et al. 2005; Nussey et al. 2005). The evolving traits that describe the reaction norms (PMRN intercept and slope) are initially assumed to be normally distributed with given mean and variance. Both traits are passed on to offspring with incomplete inheritance.

Each individual in the population has a PMRN that is characterized by a midpoint slope $(X)$, midpoint intercept $(Y)$, and envelope width. The distribution of individual PMRNs in the population represents the genetic variance (Noordwijk 1989; Windig 1994). The population-level PMRN is the mean of the individual PMRNs, and its envelope width represents the phenotypic variation in length at maturation for each age. At each age $a$, the population's phenotypic 
variance in length at maturation, $\sigma_{P, a}^{2}=\sigma_{G, a}^{2}+\sigma_{E, a}^{2}$, is composed of its genetic variance in length at maturation, $\sigma_{G, a}^{2}$, and its variance in length at maturation resulting from environmental factors, $\sigma_{E, a}^{2}$ (Noordwijk 1989; Falconer and Mackay 1996). Heritability $h_{a}^{2}$ in length at maturation at age $a$ is given by the ratio between $\sigma_{G, a}^{2}$ and $\sigma_{P, a}^{2}$ (Falconer and Mackay 1996). At each age $a$, the population's genetic variance in length at maturation is

$$
\sigma_{G, a}^{2}=a \sigma_{X}^{2}+\sigma_{Y}^{2}
$$

where $\sigma_{X}^{2}$ and $\sigma_{Y}^{2}$ are the population's additive genetic variance in midpoint slope and intercept, respectively, at age $a$. Equation (1) follows directly from the assumed linearity of PMRNs.

In our model, we assume levels of genetic variance for the two traits $X$ and $Y$ and, together with an empirical estimate of phenotypic variance in length at maturation, use it to estimate heritability in the initial population (see Section on "Initial population structure" below). The genetic variances are then free to change through time.

\section{Initial population structure}

The parameters of the initial population were estimated from Opeongo Lake creel data collected on the earliest studied cohorts (1930s and 1940s). In our model, the introduced population consists of 200 yearlings (individuals of age 1) with a normal distribution of initial body sizes based on the mean and standard deviation of the Opeongo 1932 year class. Backcalculations (Francis 1990) of body lengths at age 1, measured from scale samples collected from individuals of the 1932 cohort, were used to estimate the mean and standard deviation for yearling body size (using the validated back-calculation technique described in Dunlop and Shuter 2006). 
Erin S. Dunlop, Brian J. Shuter, Ulf Dieckmann

The initial population-level PMRN midpoint slope, midpoint intercept, and envelope width were estimated empirically from Opeongo Lake creel data using the procedure introduced by Barot et al. (2004a). This procedure involves deriving the probability of maturing at a given age $a$ and size $s$,

$$
p_{m}(a, s)=\frac{o(a, s)-o(a-1, s-\Delta s(a))}{1-o(a-1, s-\Delta s(a))}
$$

from the maturity ogive $o(a, s)$ describing the probability of being mature at a given age and size (calculated using logistic regression) and from the growth increment $\Delta s$ from age $a-1$ to age $a$ (Barot et al. 2004a). We pooled the 1930s-40s cohorts to obtain a representative sample. Sufficient data allowed the estimation of the population-level PMRN for ages 4, 5, and 6; a linear regression of the midpoints of these three ages was then used to estimate the midpoint slope and intercept of the initial population's PMRN (Figure 1a). The 1\% and 99\% maturation probability percentiles of 4-year-olds (the age class with the largest sample size) were used to determine the width of the initial population's PMRN (Figure 1a).

Given that the actual distribution of variation between midpoint slope and intercept is unknown for the considered smallmouth bass populations, we parsimoniously assume the same $10 \%$ level for the coefficients of variation $(\mathrm{CV}=100 *$ standard deviation/mean $)$ in both traits in the initial population; we chose $10 \%$ because it produces a realistic value of heritability (see below). All individuals in the initial population are then assigned a PMRN midpoint slope and intercept from a normal distribution with a mean equal to the population-level PMRN's midpoint (Figure 1a) and a standard deviation given by the assumed coefficient of variation (10\%) in midpoint slope and intercept. To examine robustness, we also determined the sensitivity of our model's results to 99 other combinations of the two coefficients of variation (Appendix 2). 
Erin S. Dunlop, Brian J. Shuter, Ulf Dieckmann

We calculated the heritability $\left(\sigma_{G, a}^{2} / \sigma_{P, a}^{2}\right)$ for 4-year-olds in our initial population. We chose this age group because this is the most common age at maturation and sample sizes are accordingly large. The value of genetic variance $\left(\sigma_{G, a}^{2}\right)$ was calculated from Equation $(1)$ and our assumed coefficients of variation. The initial population-level PMRN width for age 4 represents the range of body sizes, for this age, over which maturation occurs and was therefore used as our estimate of phenotypic variance $\left(\sigma_{P, a}^{2}\right)$ in size at maturation for this age. Using this approach, we estimated the initial population's heritability in size at maturation for age 4 as $\sim 0.26$, which is in accordance with published estimates of heritabilities in life history traits (Mousseau and Roff 1987; Law 2000).

\section{Maturation and reproduction}

In any given year, immature individuals in our model become mature according to the maturation probability given by their PMRN in conjunction with their age and size. In our model, mating is size-assortative and occurs between pairs of mature individuals (assuming a 1:1 sex ratio) that are similar in body size. We parsimoniously assume strict size-assortative mating because there is evidence that smallmouth bass are strongly size-assortative in mate preference (Ridgway et al. 1991; Mackereth et al. 1999) and we did not want to increase model complexity by introducing an additional parameter describing strength of the preference (we note that relaxing this assumption does not change the direction of predictions but does cause a slight increase in the magnitude of evolutionary change in response to size-selective mortality).

The number of offspring produced by a reproductive pair is estimated from the body size $L$ of the largest parent in the pair following an empirically derived allometric relationship (Figure $1 b)$,

$$
F_{I}=\left(H_{1} L\right)^{H_{2}}
$$


Erin S. Dunlop, Brian J. Shuter, Ulf Dieckmann

with constants $H_{1}$ and $H_{2}$. The number of new individuals recruiting to the population at age 1 is determined from a modified Ricker-type stock-recruitment function (Figure 1c),

$$
r=A S_{a}{ }^{d} e^{-b S_{a}+c T}
$$

where $S_{a}$ is the number of adults, $T$ is the mean air temperature for June through September (kept constant at $15{ }^{\circ} \mathrm{C}$ ), and $A, b, c$, and $d$ are empirically determined constants, based on a detailed analysis of annual variation in recruitment, adult population size, and summer air temperatures for the Opeongo Lake population over the period 1937-1992 (Shuter and Ridgway 2002). The survival probability from eggs to age 1 is defined as the ratio between $r$ and the total number of eggs produced by the mature population. As stock-recruitment relationships can be highly variable, we tested our model's sensitivity to adding stochastic noise to the recruitment process (Appendix 2).

To model the inheritance of quantitative traits, we assume that offspring trait values are equally determined by maternal and paternal trait values. In particular, the PMRN midpoint slope and midpoint intercept of each newborn are drawn from a normal distribution centered on the corresponding mid-parental values (mean of the two parent's trait values) and possessing a variance $\sigma_{O}^{2}$ equal to half the population variance $\sigma_{M, F}^{2}$ in the parental generation (CavalliSforza and Feldman 1976; Baskett et al. 2005),

$$
\sigma_{O}^{2}=\frac{1}{2} \sigma_{M, F}^{2} .
$$


Erin S. Dunlop, Brian J. Shuter, Ulf Dieckmann

This ensures that the inheritance process maintains the population variance and follows from the parsimonious assumption that the maternal $\sigma_{M}^{2}$ and paternal $\sigma_{F}^{2}$ trait variances are equal.

\section{Somatic growth}

We use the biphasic growth model proposed by Lester et al. (2004) to describe somatic growth. Accordingly, the growth of immature individuals is linear, with a mean growth rate $\bar{h}_{i}$ calculated from the population abundance $D$ using a simple variant of the competition equation described by Begon et al. (1996),

$$
\bar{h}_{i}=\frac{h_{\max }}{1+j D^{q}},
$$

where $j$ and $q$ are constants and $h_{\max }$ is the maximum growth rate (at $D=0$ ). Equation (6) provides a good description of the temporal association between growth and abundance exhibited by the Opeongo Lake population (Figure 1d). In the model of Lester et al. (2004), mature individuals grow according to von Bertalanffy's growth function, reaching length

$$
L_{a}=L_{\infty}\left(1-e^{-k\left(a-a_{0}\right)}\right)
$$

at age $a$, with parameters

$$
\begin{gathered}
L_{\infty}=\frac{3 h_{i}}{g}, \\
k=\ln \left(1+\frac{g}{3} \Delta a\right),
\end{gathered}
$$

and

$$
a_{0}=a_{m}+k^{-1} \ln \left(1-\frac{g}{3} a_{m}\right)
$$

where $g$ is the reproductive investment rate, $\Delta a$ is the increment between age classes ( 1 year), and $a_{m}$ is the age at which the "decision" to mature is made (this equals the age at maturation in our 
Erin S. Dunlop, Brian J. Shuter, Ulf Dieckmann

model). The reproductive investment rate $g$ was estimated from the growth curve of mature Opeongo Lake smallmouth bass (following Lester et al. 2004) captured in 2000-2001 (Dunlop et al. 2005a) and, for simplicity, is assumed to be identical and constant over time for all individuals. To allow variation in growth among individuals, growth rates $h_{i}$ are randomly drawn, separately in each year, from a normal distribution with mean $\bar{h}_{i}$ and standard deviation $h_{s}$ calculated from Opeongo Lake creel data (Shuter et al. 1987).

\section{Mortality}

Age-specific annual mortality probabilities were measured from Opeongo Lake creel data (Shuter et al. 1987) and are applied annually to individuals of ages 1 to $3, m_{1-3}=0.27$, and of ages 4 and older, $m_{4+}=0.54$. On top of this background mortality, we apply different levels of selective harvest mortality from the time of introduction onwards. We apply selective annual mortality probabilities of 0 to 0.5 (in increments of 0.1 ) at the individual level on either (i) age-0 individuals or (ii) individuals above a minimum size limit. We chose $18 \mathrm{~cm}$ as the minimum size limit because this is the hypothesized size at which mortality differences begin to emerge between the Provoking Lake and Opeongo Lake populations (Dunlop et al. 2005a). The sizeselective mortality is applied to individuals regardless of maturation status; typically, the $18 \mathrm{~cm}$ size class contains both juveniles and adults (Dunlop et al. 2005a). We also tested the sensitivity of our model results to decreasing $m_{4+}$ to 0.27 and to increasing the minimum size limit to between 20 and $28 \mathrm{~cm}$ (Appendix 2).

\section{Parental care}

We explore the consequences of parental care by considering three different ecological mechanisms. To delineate the evolutionary consequences of parental care, we investigate how the evolutionary response to a 0.3 probability of size-selective mortality, applied to individuals 
Erin S. Dunlop, Brian J. Shuter, Ulf Dieckmann

above an $18 \mathrm{~cm}$ size limit, varies in the presence and absence of each of the three mechanisms. We also assess the evolutionary effect of all three mechanisms combined.

For the first mechanism, we assume that small males possess insufficient energy reserves for nest guarding when population density is high. Accordingly, we introduce a dependence of the number $R$ of breeding mature individuals on the abundance $D_{m}$ of mature individuals in the population,

$$
R=C_{1} D_{m}{ }^{C_{2}}
$$

where $C_{1}$ and $C_{2}$ are empirically based constants (Figure 1e). The largest $R$ mature individuals in the population are then chosen for breeding, implying that for $R<D_{m}$ the smallest mature individuals in the population do not breed.

For the second mechanism, we assume elevated mortality levels for parents that breed at small body sizes. We used mark-recapture data on nesting males in Opeongo Lake to derive the relationship between the size of a parent and its mortality (Figure 1f; Appendix 3). We incorporate this second mechanism by applying the mortality probability $M_{p, L}$ to the largest parent in each reproducing pair, following reproduction.

For the third mechanism, we assume reduced survival of offspring of small-sized parents. Due to a lack of empirical data for calibrating this effect, we assume a linearly decreasing relationship between the mortality probability of the offspring produced by a given pair of parents in a given year and the size $L$ of the pair's larger parent. Specifically, we assume this mortality probability to decrease from a maximum of $\tilde{M}_{p, 0}=0.5$ at $L=0 \mathrm{~cm}$ to a minimum of 0 at $L \geq L_{0}$,

$$
\tilde{M}_{p, s}=\tilde{M}_{p, 0}\left(1-L / L_{0}\right)_{+} .
$$


Erin S. Dunlop, Brian J. Shuter, Ulf Dieckmann

We chose $L_{0}=40 \mathrm{~cm}$ because parents above this size appear to be particularly aggressive and

effective nest guarders (E. Dunlop, unpublished data). We also varied $\tilde{M}_{p, 0}$ to observe the effect on model results (Appendix 2).

\section{Results}

Age-0 smallmouth bass mortality causes slower population expansion, lower population biomass and abundance, faster somatic growth rates, and maturation at slightly larger sizes (Table 1; Figure 2); however, there is little to no effect on the PMRN's slope and intercept (Figure 2e). Selective mortality of individuals above $18 \mathrm{~cm}$ in the absence of parental care has a small influence on population abundance and somatic growth rate, but causes a substantial decrease in population biomass and in age and size at maturation (Table 1; Figure 2); these changes are accompanied by large decreases in the PMRN's slope and intercept (Figure 2f).

Including effects of parental care generally reduces the rate of evolution. The 100-year response in the PMRN to a 0.3 probability of size-selective mortality is not appreciably different when we make the number of small-sized parents that actually breed dependent on the abundance of adults (mechanism 1), but it is significantly reduced when we include a survival cost for small parents (mechanism 2), include a survival cost for the offspring of small-sized parents (mechanism 3), or combine all three mechanisms (Table 1; Figure 3). In addition, final population sizes are significantly reduced when these parental care effects are included (Table 1).

\section{Discussion}

Our model predicts that, at least in the absence of parental care, introduction of a population into a system with high size-selective mortality causes a dramatic shift of the PMRN, 
Erin S. Dunlop, Brian J. Shuter, Ulf Dieckmann

corresponding to evolution towards smaller sizes and younger ages at maturation. This is because individuals able to reach maturation prior to succumbing to mortality are more likely to reproduce and pass on their traits to the next generation. These predictions are supported by observations of PMRN shifts in several stocks of cod Gadus morhua (Barot et al. 2004b; Olsen et al. 2004, 2005) and plaice Pleuronectes platessa (Grift et al. 2003) that have been subject to the type of selective mortality we considered in our model. In northern cod, the midpoint of the PMRN dropped by $10 \mathrm{~cm}$ in only 7 years (Olsen et al. 2004), providing empirical evidence that the magnitude of responses predicted from our model are also possible in nature. However, these predictions contrast sharply with the observed stability of the PMRN exhibited by both the Provoking and Opeongo Lake smallmouth bass populations after 100 years of living under different mortality rates (Dunlop et al. 2005a, b).

Not surprisingly, age-0 smallmouth bass mortality causes no evolutionary response in the PMRN. In our model, age-0 smallmouth bass mortality is applied to individuals during their first year of life and is not applied throughout the juvenile period. We take this approach because many predators of smallmouth bass are relatively small in body size and tend to feed on the smallmouth bass' egg and larval stages (Knotek and Orth 1998; Dorn and Mittelbach 2004; Steinhart et al. 2004). Our approach is in contrast to models in which the life history strategy affects survival throughout the juvenile period (e.g., Abrams and Rowe 1996) or in which the considered juvenile mortality extends right up to maturation (e.g., Ernande et al. 2004); in these models, juvenile mortality is predicted to cause evolution in the age or size at maturation. However, because mortality during the age- 0 phase occurs far in advance of maturation, so that individuals have to undergo such mortality regardless of their maturation traits, it is clear that the age-0 smallmouth bass mortality in our model exerts no selective pressure on the PMRN. 
Erin S. Dunlop, Brian J. Shuter, Ulf Dieckmann

The detailed studies that have been conducted on the Provoking Lake and Opeongo Lake smallmouth bass populations permit comparisons between model predictions and empirical observations. Our model predicts that introduction to a system with low mortality on age-0 individuals produces higher population density, slower somatic growth rates, and smaller sizes at maturation. These model predictions match the empirical observations of the Provoking Lake population, where evidence suggests that there is less predation of age- 0 individuals relative to the Opeongo Lake population (Dunlop et al. 2005a). Empirical evidence also suggests that mortality on typically adult size classes is higher in Provoking Lake than in Opeongo Lake (Orendorff 1983; Dunlop et al. 2005a); for example, mortality probabilities following nest guarding, estimated from return rates of tagged individuals, are related to body size (Figure 1f) and average $89 \%$ in Provoking Lake and 63\% in Opeongo Lake (Dunlop et al. 2005a). These differences in mortality are not due to recreational fishing because harvest is low in the Opeongo Lake population (Shuter et al. 1987) and very low (less than 3\% per year) in the Provoking Lake population (Orendorff 1983), but are instead likely related to the low availability of large prey in Provoking Lake (Dunlop et al. 2005a). Interestingly however, these differences in size-selective mortality between the Provoking Lake and Opeongo Lake populations have not led to detectable evolutionary divergence in their PMRNs (Dunlop et al. 2005b).

The predictions of our model, namely that parental care reduces the rate of evolutionary response to mortality, are supported by the above observations on the Opeongo Lake and Provoking Lake populations showing no evolutionary divergence in their PMRNs despite between-population differences in size-selective mortality. Inclusion of parental care mechanisms in our model alters the selective environment and reduces the evolutionary response in the PMRN. In the wild, larger parents not only possess higher energy reserves to better survive the energetic costs of nest guarding (Mackereth et al. 1999), but are also better able to 
Erin S. Dunlop, Brian J. Shuter, Ulf Dieckmann

defend their brood from predators (Wiegmann and Baylis 1995; Knotek and Orth 1998). Large body size also has its benefits in species without parental care, in which larger, more experienced spawners produce eggs and larvae with higher survival probabilities (e.g., Trippel 1998). Our model illustrates that the selective pressures favoring large body size in parents might counteract the selective pressures towards maturation at smaller body size imposed by mortality on larger individuals, thereby altering the total selective forces acting on the PMRN. However, this is not to say that very intensive harvest will not cause substantial evolution of the PMRN in a species with parental care; rather, the evolutionary response to intense harvest would likely be lessened in a species with parental care compared to one without parental care because of the opposing selective forces. This increase in 'evolutionary inertia', imposed on the PMRN by parental care effects, has demographic consequences: final population sizes in the presence of parental care are reduced. This reduction occurs because parental care effects constrain the compensating increases in population growth rate that arise from evolutionary adaptation in the PMRN. This finding suggests that the presence of parental care can impose additional limitations on the ability of a population to persist, by adaptation, in the face of the added mortality imposed by intense harvest.

Observed patterns in the age and size at maturation of smallmouth bass support our hypothesis that the survival costs associated with parental care are significant factors in this system. The lower range of ages and sizes at maturation that our model predicts for a species without parental care experiencing the high-mortality regimes are not commonly observed in smallmouth bass, neither in the Provoking Lake or Opeongo Lake populations (Dunlop et al. 2005a), nor in wild populations of smallmouth bass in general (Dunlop 2005). However, once we include parental care in the model, maturation occurs across a range of more typical ages and 
Erin S. Dunlop, Brian J. Shuter, Ulf Dieckmann

sizes, suggesting that accounting for this life history characteristic improves the realism of our model.

Our evolutionary model includes several simplifications. First, the model describes evolution in quantitative traits rather than genes. Second, we parsimoniously assume coefficients of genetic variation of $10 \%$ in our initial population. As expected (Falconer and Mackay 1996), the speed of evolution is positively related to the assumed values (Appendix 2). Encouragingly, however, our assumed coefficient results in an estimated heritability of length at maturation for 4year-olds $(\sim 0.26)$ that is the same as the mean value of 0.26 reported for life history traits by Mousseau and Roff (1987). Third, we assume no genetic correlation between the two evolving quantitative traits, and we do not consider potential joint evolution in many other interesting life history traits, such as reproductive investment or somatic growth rate. We did not allow these other traits to evolve in the model because the inclusion of PMRNs already is a substantial advancement over previous models and we wanted to keep model analyses and predictions reasonably simple. However, there is evidence that reproductive investment increases with higher mortality (Reznick et al. 1990; Lester et al. 2004) and that rapid evolution of somatic growth rate can occur in response to selective mortality on large individuals (Conover and Munch 2002); it is thus conceivable that size-selective mortality could induce evolutionary shifts in these other life history traits in the smallmouth bass.

A promising extension of our model would be to include sex differences. In our model, males and females are assumed to be identical, with a 1:1 sex ratio. We made this simplification because there is no sexual dimorphism in the somatic growth rates of smallmouth bass (Dunlop et al. 2005a). This is likely because females invest a large amount of energy into gonads, whereas males invest energy into parental care, leading to a similar reduction in somatic growth in both sexes. If we had modeled males and females separately and allowed only males to exhibit 
Erin S. Dunlop, Brian J. Shuter, Ulf Dieckmann

parental care, the impact on the parental care results would have likely been minimal because of size-assortative mating (Ridgway et al. 1991; Mackereth et al. 1999). In the wild, small females might not be able to breed if there are no small males for them to breed with (Dunlop et al. 2005a); if the number of small males that breed is dependent on population density (our first parental care mechanism), the same relationship will hold true for small females. Similarly, because of size-assortative mating, the offspring of large females will also have a higher probability of survival (our third parental care mechanism). When considering a mortality cost for small parents (our second parental care mechanism), we only apply this cost to one of the parents to mimic a situation where only one parent is providing care. Therefore, modeling separate sexes was not necessary for the purposes of this study but, in future, could provide further insights depending on the focal species and research question at hand.

The eco-genetic modeling framework presented here provides a powerful tool for studying the mortality-induced evolution of PMRNs. The majority of related models to date have not adequately considered phenotypic plasticity in the maturation process, since they directly modeled age and/or size at maturation as quantitative traits, without accounting for their dependence on the environment (e.g., Law 1979; Abrams and Rowe 1996; Heino 1998; MartinezGarmendia 1998; Ratner and Lande 2001). The model by Ernande et al. (2004) did account for phenotypic plasticity by following the evolution of MRNs, but employed deterministic maturation dynamics and focused on the prediction of evolutionary endpoints rather than of the time course of evolutionary change. In Ernande et al. (2004), size-selective harvest of individuals larger than a minimum size limit caused evolutionary shifts of the MRN towards younger ages and smaller sizes. While these findings are qualitatively similar to ours, using an eco-genetic modeling approach readily allowed for several novel developments. First, we could model maturation as being probabilistic, which is likely more realistic given the considerable 
Erin S. Dunlop, Brian J. Shuter, Ulf Dieckmann

stochasticity involved in the maturation process (Heino et al. 2002). This added realism actually alters the model's predictions by slowing down the evolutionary response as compared with models in which MRNs are unrealistically treated as deterministic (Appendix 2). Second, our choice of model allowed examination of the speed of evolution, something that is not possible based on traditional optimization models (e.g., Law 1979) or adaptive dynamics models (e.g., Heino 1998; Ernande et al. 2004), both of which focus on evolutionary endpoints instead. Third, our model permitted somatic growth rates to vary with population density, a realistic feature missing from most related previous evolutionary models (e.g., Martinez-Garmendia 1998; Ratner and Lande 2001; Ernande et al. 2004; Tenhumberg et al. 2004; Baskett et al. 2005). Modeling somatic growth as density-dependent is important in the context of mortality-induced evolution: while mortality can influence growth through its impact on population abundance, growth controls an individual's body size, which in turn influences its fitness, especially in an environment where mortality is size-selective. Accounting for density-dependent growth is also important when examining the dynamics of recently introduced populations, as the density and growth of such populations undergo considerable temporal shifts in the wake of the introduction. Our analysis of the effect of growth on the evolutionary process clearly illustrates the danger in assuming a constant growth rate that does not change with population abundance: the rates of evolution can be either severely over- or under-estimated when density-dependence is not included (Appendix 2). Also, we would not have been able to predict the plastic effect of age-0 mortality (which alters abundance) on growth and maturation patterns without the presence of density-dependent growth.

Finally, and perhaps most importantly, our results are novel because we show that inherent selective forces, such as those produced by parental care, can greatly alter the evolutionary response typically observed under size-selective harvest. This underscores the 
Erin S. Dunlop, Brian J. Shuter, Ulf Dieckmann

importance of adequately reflecting the life history characteristics of the considered species when assessing its vulnerability to the selective pressures imposed by exploitation.

\section{Acknowledgements}

We thank the Harkness Laboratory of Fisheries Research where data on the Opeongo Lake and Provoking Lake smallmouth bass populations were collected. We appreciate helpful comments on earlier drafts of this manuscript by P. Abrams, P. Boudry, B. Ernande, M. Heino, J. Hutchings, N. Lester, J. Orendorff, M. Ridgway, and H. Rodd. This research was carried out as part of the Young Scientist Summer Program 2004 at the International Institute for Applied Systems Analysis. E.D. and U.D. gratefully acknowledge financial support by the Marie Curie Research Training Network FishACE (Fisheries-induced Adaptive Changes in Exploited Stocks), funded by the European Community's Sixth Framework Programme. Additional support was provided by the Natural Sciences and Engineering Research Council of Canada, the University of Toronto, and the Ontario Ministry of Natural Resources.

\section{Literature cited}

Abrams, P.A., and L. Rowe. 1996. The effects of predation on the age and size of maturity of prey. Evolution 50:1052-1061.

Barot, S., M. Heino, L. O'Brien, and U. Dieckmann. 2004a. Estimating reaction norms for age and size at maturation when age at first reproduction is unknown. Evolutionary Ecology Research 6:659-678.

Barot, S., M. Heino, L. O'Brien, and U. Dieckmann. 2004b. Long-term trend in the maturation reaction norm of two cod stocks. Ecological Applications 14:1257-1271. 
Erin S. Dunlop, Brian J. Shuter, Ulf Dieckmann

Baskett, M.L., S.A. Levin, S.D. Gaines, and J. Dushoff. 2005. Marine reserve design and the evolution of size at maturation in harvested fish. Ecological Applications 15:882-901.

Begon, M., J.L. Harper, and C. Townsend. 1996. Ecology: Individuals, Populations and Communities, Third edition. Blackwell Science, Oxford, UK.

Bernardo, J. 1993. Determinants of maturation in animals. Trends in Ecology and Evolution $8: 166-173$.

Brommer, J.E., J. Merilä, B.C. Sheldon, and L. Gustafsson. 2005. Natural selection and genetic variation for reproductive reaction norms in a wild bird population. Evolution 59:13621371.

Cavalli-Sforza, L.L., and M.W. Feldman. 1976. Evolution of continuous variation: Direct approach through joint distribution of genotypes and phenotypes. Proceedings of the Royal Society of London Series B - Biological Sciences 73:1689-1692.

Clutton-Brock, T.H. 1991. The Evolution of Parental Care. Princeton University Press, Princeton, New Jersey, USA.

Conover, D.O., and S.B. Munch. 2002. Sustaining fisheries yields over evolutionary time scales. Science 297:94-96.

de Jong, G. 1990. Quantitative genetics of reaction norms. Journal of Evolutionary Biology $3: 447-468$.

Dorn, N.J., and G.G. Mittelbach. 2004. Effects of a native crayfish (Orconectes virilis) on the reproductive success and nesting behavior of sunfish (Lepomis spp.). Canadian Journal of Fisheries and Aquatic Sciences 61:2135-2143.

Dunlop, E.S. 2005. Patterns and process of life history variation in the smallmouth bass, Micropterus dolomieu. Ph.D. Thesis. University of Toronto, Toronto, Canada. 
Erin S. Dunlop, Brian J. Shuter, Ulf Dieckmann

Dunlop, E.S. and B.J. Shuter. 2006. Introduced and native populations of smallmouth bass differ in the concordance between climate and somatic growth. Transactions of the American Fisheries Society 135:1175-1190.

Dunlop, E.S., J.A. Orendorff, B.J. Shuter, F.H. Rodd, and M.S. Ridgway. 2005a. Diet and divergence of introduced smallmouth bass, Micropterus dolomieu, populations. Canadian Journal of Fisheries and Aquatic Sciences 62:1720-1732.

Dunlop, E.S., B.J. Shuter, and M.S. Ridgway. 2005b. Isolating the influence of growth rate on maturation patterns in the smallmouth bass, Micropterus dolomieu. Canadian Journal of Fisheries and Aquatic Sciences 62:844-853.

Ernande, B., U. Dieckmann, and M. Heino. 2004. Adaptive changes in harvested populations: Plasticity and evolution of age and size at maturation. Proceedings of the Royal Society of London Series B-Biological Sciences 271:415-423.

Falconer, D.S., and T.F.C. Mackay. 1996. Introduction to Quantitative Genetics, Fourth edition. Longman, Essex, UK.

Francis, R.I.C.C. 1990. Back-calculation of fish length: A critical review. Journal of Fish Biology $36: 883-902$.

Grift, R.E., A.D. Rijnsdorp, S. Barot, M. Heino, and U. Dieckmann. 2003. Fisheries-induced trends in reaction norms for maturation in North Sea plaice. Marine Ecology - Progress Series 257:247-257.

Haugen, T. O., and L. A. Vøllestad. 2001. A century of life-history evolution in grayling. Genetica 112:475-491.

Heino, M. 1998. Management of evolving fish stocks. Canadian Journal of Fisheries and Aquatic Sciences 55:1971-1982. 
Erin S. Dunlop, Brian J. Shuter, Ulf Dieckmann

Heino, M., U. Dieckmann, and O.R. Godø. 2002. Measuring probabilistic reaction norms for age and size at maturation. Evolution 56:669-678.

Hutchings, J.A. 2004. The cod that got away. Nature 428:899-900.

Knotek, W.L., and D.J. Orth. 1998. Survival for specific life intervals of smallmouth bass, Micropterus dolomieu, during parental care. Environmental Biology of Fishes 51:285296.

Law, R. 1979. Optimal life histories under age-specific predation. American Naturalist 114:399417.

Law, R. 2000. Fishing, selection, and phenotypic evolution. ICES Journal of Marine Science 57:659-668.

Lester, N.P., B.J. Shuter, and P.A. Abrams. 2004. Interpreting the von Bertalanffy model of somatic growth in fish: the cost of reproduction. Proceedings of the Royal Society of London Series B - Biological Sciences 271:1625-1631.

Mackereth, R.W., D.L.G. Noakes, and M.S. Ridgway. 1999. Size-based variation in somatic energy reserves and parental expenditure by male smallmouth bass, Micropterus dolomieu. Environmental Biology of Fishes 56:263-275.

Mank, J.E., D.E.L. Promislow, J.C. Avise. 2005. Phylogenetic perspectives in the evolution of parental care in ray-finned fishes. Evolution 59:1570-1578.

Martinez-Garmendia, J. 1998. Simulation analysis of evolutionary response of fish populations to size-selective harvesting with the use of an individual-based model. Ecological Modelling 111:37-60.

Mousseau, T.A., and D.A. Roff. 1987. Natural selection and the heritability of fitness components. Heredity 59:181-198.

Noordwijk, A.J. v. 1989. Reaction norms in genetical ecology. Bioscience 39:453-458. 
Erin S. Dunlop, Brian J. Shuter, Ulf Dieckmann

Nussey, D.H., E. Postma, P. Gienapp, and M.E. Visser. 2005. Selection on heritable phenotypic plasticity in a wild bird population. Science 310:304-306.

Olsen, E.M., M. Heino, G.R. Lilly, M.J. Morgan, J. Brattey, B. Ernande, and U. Dieckmann. 2004. Maturation trends indicative of rapid evolution preceded the collapse of northern cod. Nature 428:932-935.

Olsen, E.M., G.R. Lilly, M. Heino, M.J. Morgan, J. Brattey, and U. Dieckmann. 2005. Assessing changes in age and size at maturation in collapsing populations of Atlantic cod (Gadus morhua). Canadian Journal of Fisheries and Aquatic Sciences 62:811-823.

Orendorff, J.A. 1983. The relationship of feeding, growth and maturation in three northern smallmouth bass, Micropterus dolomieui, Lacépède, populations. M.Sc. University of Toronto, Toronto, Canada.

Ratner, S., and R. Lande. 2001. Demographic and evolutionary responses to selective harvesting in populations with discrete generations. Ecology 82:3093-3104.

Reznick, D.A., H. Bryga, and J.A. Endler. 1990. Experimentally induced life-history evolution in a natural population. Nature 346:357-359.

Reznick, D.A., and C.K. Ghalambor. 2005. Can commercial fishing cause evolution? Answers from guppies. Canadian Journal of Fisheries and Aquatic Sciences 62:791-801.

Reznick, D. N. 1993. Norms of reaction in fishes. Pages 72-90 in T.K. Stokes, J.M. McGlade, and R. Law, editors. The Exploitation of Evolving Resources. Springer-Verlag, Berlin, Germany.

Ridgway, M.S. 1988. Developmental stage of offspring and brood defense in smallmouth bass (Micropterus dolomieui). Canadian Journal of Zoology 66:1722-1728.

Ridgway, M.S. 1989. The parental response to brood size manipulation in smallmouth bass (Micropterus dolomieui). Ethology 80:47-54. 
Erin S. Dunlop, Brian J. Shuter, Ulf Dieckmann

Ridgway, M.S., and T.G. Friesen. 1992. Annual variation in parental care in smallmouth bass, Micropterus dolomieu. Environmental Biology of Fishes 35:243-255.

Ridgway, M.S., and B.J. Shuter. 1994. The effects of supplemental food on reproduction in parental male smallmouth bass. Environmental Biology of Fishes 59:201-207.

Ridgway, M.S., B.J. Shuter, T.A. Middel, and M.L. Gross. 2002. Spatial ecology and densitydependent processes in smallmouth bass: The juvenile transition hypothesis. Pages 47-60 in D. P. Philipp and M. S. Ridgway, editors. Black Bass: Ecology, Conservation, and Management. American Fisheries Society Symposium 31, Bethesda, Maryland, USA.

Ridgway, M.S., B.J. Shuter, and E.E. Post. 1991. The relative influence of body size and territorial behaviour on nesting asynchrony in male smallmouth bass, Micropterus dolomieui (Pisces: Centrarchidae). Journal of Animal Ecology 60:665-681.

Rijnsdorp, A.D. 1993. Fisheries as a large-scale experiment on life-history evolution Disentangling phenotypic and genetic-effects in changes in maturation and reproduction of North Sea Plaice, Pleuronectes platessa L. Oecologia 96:391-401.

Robbins, W.H., and H.R. MacCrimmon. 1974. The Blackbass in America and Overseas. Biomanagement and Research Enterprises, Sault Ste. Marie, Ontario, Canada.

Roff, D.A. 1992. The Evolution of Life Histories; Theory and Analysis. Chapman \& Hall, New York, USA.

Shuter, B.J., J.A. MacLean, F.E.J. Fry, and H.A. Regier. 1980. Stochastic simulation of temperature effects on first-year survival of smallmouth bass. Transactions of the American Fisheries Society 109:1-34.

Shuter, B.J., J.E. Matuszek, and H.A. Reiger. 1987. Optimal use of creel survey data in assessing population behaviour: Lake Opeongo lake trout (Salvelinus namaycush) and smallmouth 
Erin S. Dunlop, Brian J. Shuter, Ulf Dieckmann

bass (Micropterus dolomieui), 1936-83. Canadian Journal of Fisheries and Aquatic Sciences 44:229-238.

Shuter, B. J., and J. R. Post. 1990. Climate, population viability, and the zoogeography of temperate fishes. Transactions of the American Fisheries Society 119:314-336.

Shuter, B.J., and M.S. Ridgway. 2002. Bass in time and space: operational definitions of risk. Pages 235-250 in D.P. Philipp and M.S. Ridgway, editors. Black Bass: Ecology, Conservation, and Management. American Fisheries Society Symposium 31, Bethesda, Maryland, USA.

Stearns, S.C., and J.C. Koella. 1986. The evolution of phenotypic plasticity in life-history traits Predictions of reaction norms for age and size at maturity. Evolution 40:893-913.

Steinhart, G.B., E.A. Marschall, and R.A. Stein. 2004. Round goby predation on smallmouth bass offspring in nests during simulated catch-and-release angling. Transactions of the American Fisheries Society 133:121-131.

Tenhumberg, B., A.J. Tyre, A.R. Pople, and H.P. Possingham. 2004. Do harvest refuges buffer kangaroos against evolutionary responses to selective harvesting? Ecology 85:2003-2017.

Trippel, E.A. 1998. Egg size and viability and seasonal offspring production of young Atlantic cod. Transactions of the American Fisheries Society 127:339-359.

Wiegmann, D.D., and J.R. Baylis. 1995. Male body size and paternal behaviour in smallmouth bass, Micropterus dolomieui (Pisces: Centrarchidae). Animal Behaviour 50:1543-1555.

Windig, J.J. 1994. Reaction norms and the genetic basis of phenotypic plasticity in the wing pattern of the butterfly Bicyclus anynana. Journal of Evolutionary Biology 7:665-695. 
Erin S. Dunlop, Brian J. Shuter, Ulf Dieckmann

Table 1. Detailed model results. Population characteristics (mean \pm 1 standard deviation for 100 independent model runs) after 100 years of annual selective mortality probability $m$ on either age-0 individuals or individuals larger than $18 \mathrm{~cm}$.

\begin{tabular}{|c|c|c|c|c|c|c|c|}
\hline $\begin{array}{l}\text { Parental } \\
\text { care } \\
\text { effects }\end{array}$ & $\begin{array}{l}\text { Targets of } \\
\text { selective } \\
\text { mortality }\end{array}$ & $m$ & $\begin{array}{l}\text { Age at } \\
\text { maturation } \\
\text { (years) }\end{array}$ & $\begin{array}{l}\text { Size at } \\
\text { maturation } \\
(\mathrm{cm})\end{array}$ & $\begin{array}{l}\text { Immature } \\
\text { growth rate } \\
\left(\mathrm{cm} \mathrm{year}^{-1} \text { ) }\right.\end{array}$ & $\begin{array}{l}\text { Asymptotic } \\
\text { length } \\
(\mathrm{cm})\end{array}$ & $\begin{array}{l}\text { Total } \\
\text { population } \\
\text { abundance }\end{array}$ \\
\hline 0 & age- 0 & 0.1 & $3.3 \pm 0.2$ & $21.1 \pm 1.2$ & $6.2 \pm 0.0$ & $50.3 \pm 0.2$ & $9,714 \pm 340$ \\
\hline 0 & age- 0 & 0.2 & $3.3 \pm 0.2$ & $21.4 \pm 1.4$ & $6.3 \pm 0.0$ & $51.0 \pm 0.3$ & $8,059 \pm 481$ \\
\hline 0 & age- 0 & 0.3 & $3.3 \pm 0.2$ & $21.6 \pm 1.4$ & $6.4 \pm 0.0$ & $51.9 \pm 0.3$ & $6,350 \pm 470$ \\
\hline 0 & age-0 & 0.4 & $3.4 \pm 0.2$ & $22.4 \pm 1.5$ & $6.6 \pm 0.0$ & $53.2 \pm 0.4$ & $4,460 \pm 450$ \\
\hline 0 & age- 0 & 0.5 & $3.3 \pm 0.2$ & $23.0 \pm 1.4$ & $6.8 \pm 0.1$ & $55.0 \pm 0.6$ & $2,722 \pm 382$ \\
\hline 0 & $>18 \mathrm{~cm}$ & 0.1 & $2.9 \pm 0.2$ & $18.3 \pm 1.7$ & $6.2 \pm 0.0$ & $50.0 \pm 0.2$ & $10,480 \pm 477$ \\
\hline 0 & $>18 \mathrm{~cm}$ & 0.2 & $2.5 \pm 0.3$ & $16.0 \pm 2.1$ & $6.2 \pm 0.1$ & $50.2 \pm 0.4$ & $9,807 \pm 785$ \\
\hline 0 & $>18 \mathrm{~cm}$ & 0.3 & $2.2 \pm 0.3$ & $13.9 \pm 2.4$ & $6.2 \pm 0.1$ & $50.5 \pm 0.7$ & $9,271 \pm 1169$ \\
\hline 0 & $>18 \mathrm{~cm}$ & 0.4 & $1.9 \pm 0.3$ & $11.8 \pm 2.3$ & $6.2 \pm 0.1$ & $50.6 \pm 1.0$ & $8,954 \pm 1451$ \\
\hline 0 & $>18 \mathrm{~cm}$ & 0.5 & $1.7 \pm 0.3$ & $10.7 \pm 2.7$ & $6.3 \pm 0.2$ & $50.9 \pm 1.6$ & $8,475 \pm 1704$ \\
\hline 1 & $>18 \mathrm{~cm}$ & 0.3 & $3.1 \pm 0.0$ & $19.6 \pm 0.3$ & $6.3 \pm 0.0$ & $51.2 \pm 0.4$ & $7,706 \pm 628$ \\
\hline 2 & $>18 \mathrm{~cm}$ & 0.3 & $2.9 \pm 0.3$ & $20.1 \pm 2.3$ & $6.8 \pm 0.2$ & $54.9 \pm 1.3$ & $3,363 \pm 1098$ \\
\hline 3 & $>18 \mathrm{~cm}$ & 0.3 & $2.4 \pm 0.3$ & $15.4 \pm 2.6$ & $6.3 \pm 0.1$ & $50.9 \pm 1.0$ & $8,472 \pm 1681$ \\
\hline 123 & $>18 \mathrm{~cm}$ & 0.3 & $3.3 \pm 0.2$ & $23.7 \pm 1.7$ & $7.1 \pm 0.1$ & $57.6 \pm 0.8$ & $1,615 \pm 374$ \\
\hline
\end{tabular}

Parental care effects: $0=$ no parental care mechanism, $1=$ small parents do not breed if the number of adults is large, $2=$ small parents experience survival cost, $3=$ offspring of small parents experience survival cost $\left(\tilde{M}_{p, 0}=0.5\right)$, and $123=$ all three parental care mechanisms combined. 
Erin S. Dunlop, Brian J. Shuter, Ulf Dieckmann

\section{Figure captions}

Figure 1. Empirically derived functions. (a) Probabilistic maturation reaction norm estimated for the Opeongo Lake population in the 1930s-40s showing the 50\% (midpoint), $1 \%$, and $99 \%$ probability curves. (b) Relationship between fecundity and body size for Provoking Lake and Opeongo Lake (reproduced from Dunlop et al. 2005a). (c) Stock-recruitment relationship for the Opeongo Lake population (reproduced from Shuter and Ridgway 2002). (d) Relationship between immature somatic growth rate and population abundance for the Opeongo Lake population (reproduced from Shuter et al. 1987). (e) Relationship between the number of breeding males and adult males used in parental care mechanism 1 (continuous line; reproduced from Ridgway et al. 2002); the dashed line shows the 1:1 relationship. (f) Relationship between annual mortality probability and fork length of male nest-guarders used in parental care mechanism 2 (reproduced from Dunlop et al. 2005b; Appendix 3).

Figure 2. Model results in the absence of parental care, for different levels of selective mortality probability ( 0 to 0.5 ; line thickness increases with increasing mortality probability) on either age0 individuals or individuals larger than $18 \mathrm{~cm}$. All results are averaged for 100 independent model runs. (a) Population biomass \pm 1 standard deviation (every $10^{\text {th }}$ year) for mortality on age0 individuals. (b) Population biomass \pm 1 standard deviation for mortality on individuals larger than $18 \mathrm{~cm}$. (c) Immature somatic growth rate \pm 1 standard deviation for mortality on age- 0 individuals. (d) Immature somatic growth rate \pm 1 standard deviation for mortality on individuals larger than $18 \mathrm{~cm}$. (e) Final position (year 100) of population-level probabilistic maturation reaction norm (PMRN) midpoint for mortality on age-0 individuals. (f) Final population-level PMRN midpoint for mortality on individuals larger than $18 \mathrm{~cm}$. Biomass was estimated by 
Erin S. Dunlop, Brian J. Shuter, Ulf Dieckmann

converting body length to body mass using an empirically derived length-weight relationship (data from Dunlop et al. 2005a).

Figure 3. Influence of parental care on model results with an annual selective mortality probability of 0.3 on individuals larger than $18 \mathrm{~cm}$. All results are averaged over 100 independent model runs. (a) Changes in probabilistic maturation reaction norm (PMRN) midpoint slope in the absence of parental care (०), when small parents do not breed if the number of adults is large (1), when small parents experience a survival cost (2), when the offspring of small parents experience a survival cost $\left(3\right.$, with $\left.\widetilde{M}_{p, 0}=0.5\right)$, and when all three effects of parental care are combined (x). (b) Corresponding changes in PMRN midpoint intercept. 
Erin S. Dunlop, Brian J. Shuter, Ulf Dieckmann

Figure 1.
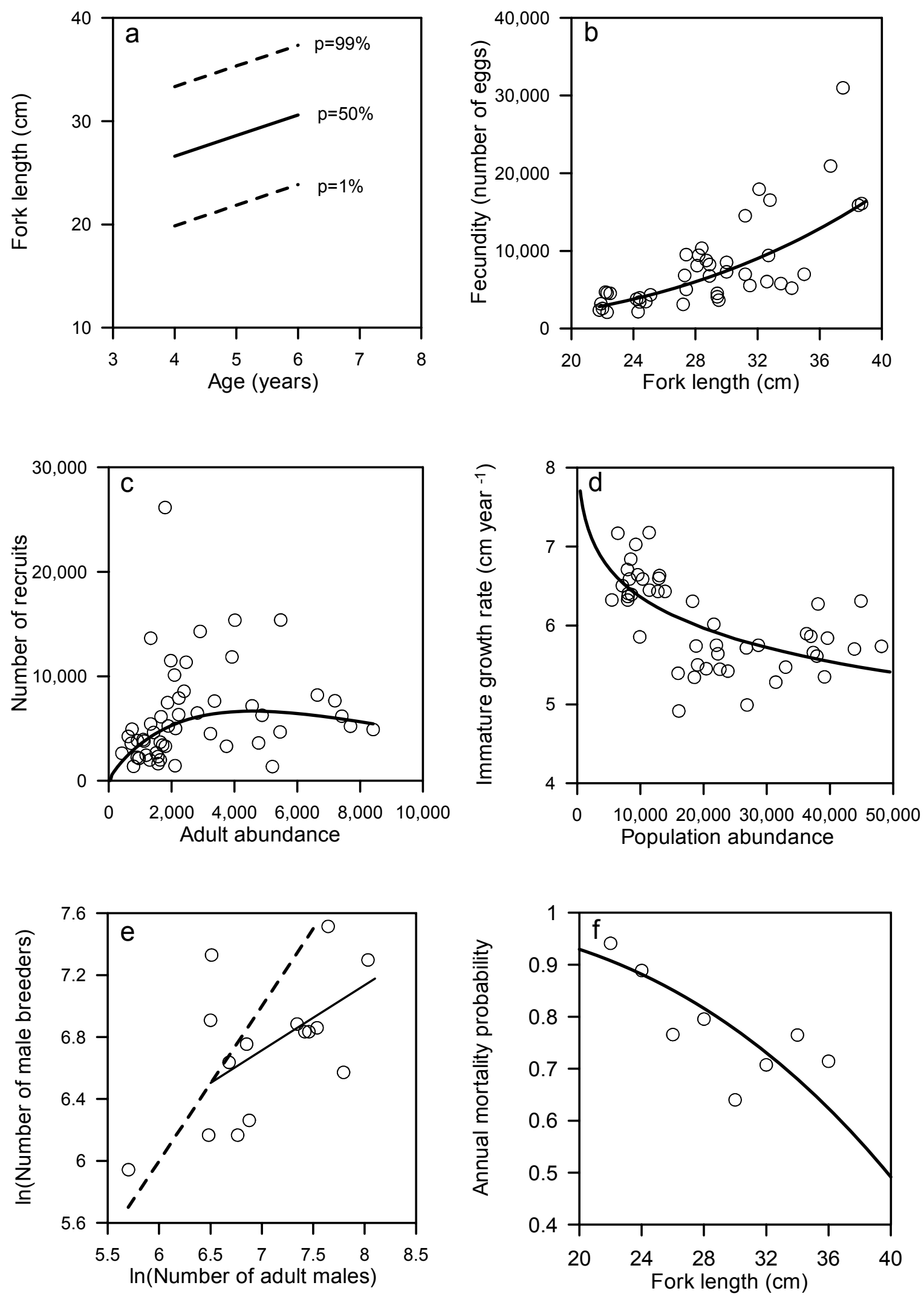
Erin S. Dunlop, Brian J. Shuter, Ulf Dieckmann

Figure 2.
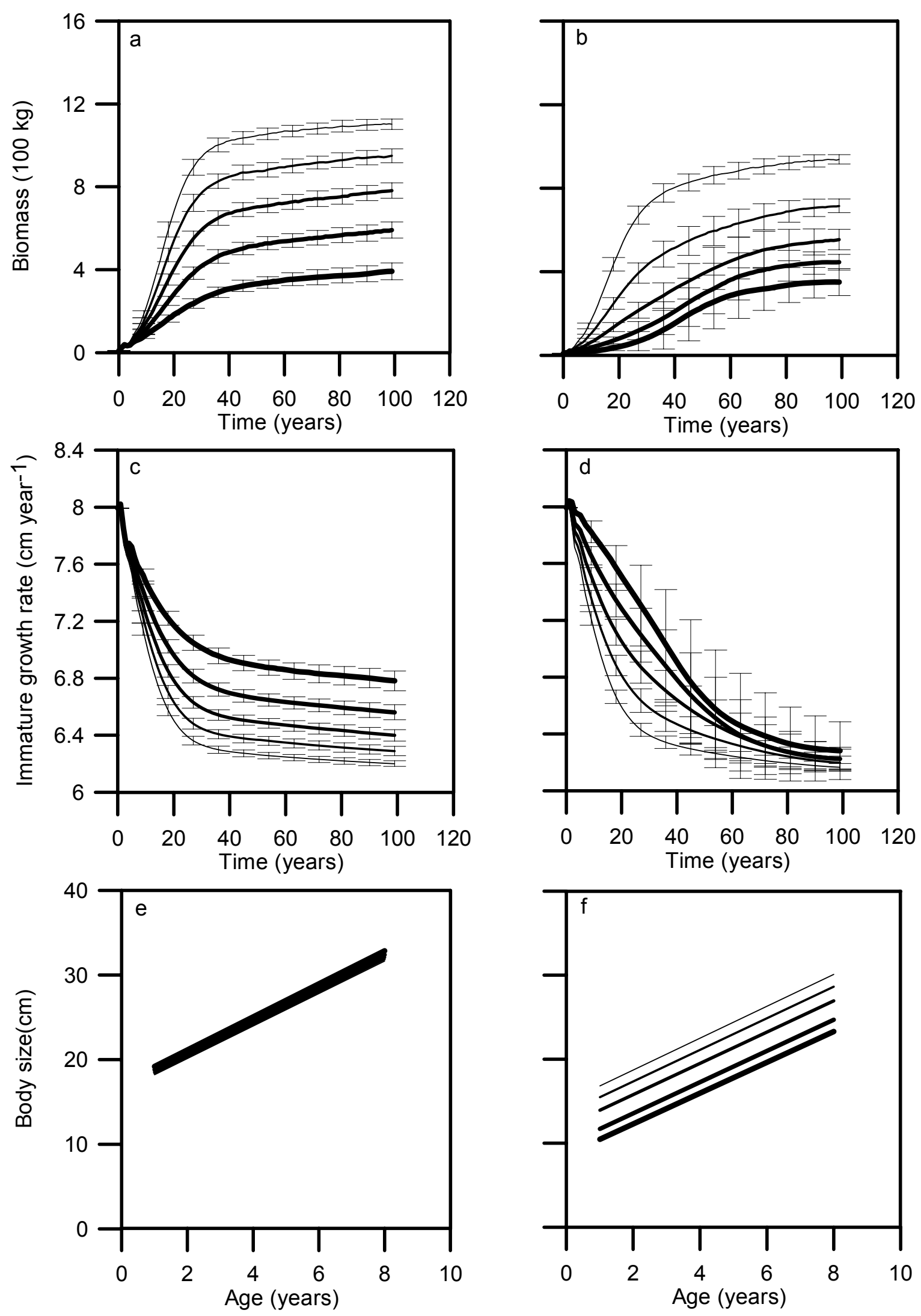
Erin S. Dunlop, Brian J. Shuter, Ulf Dieckmann

Figure 3.
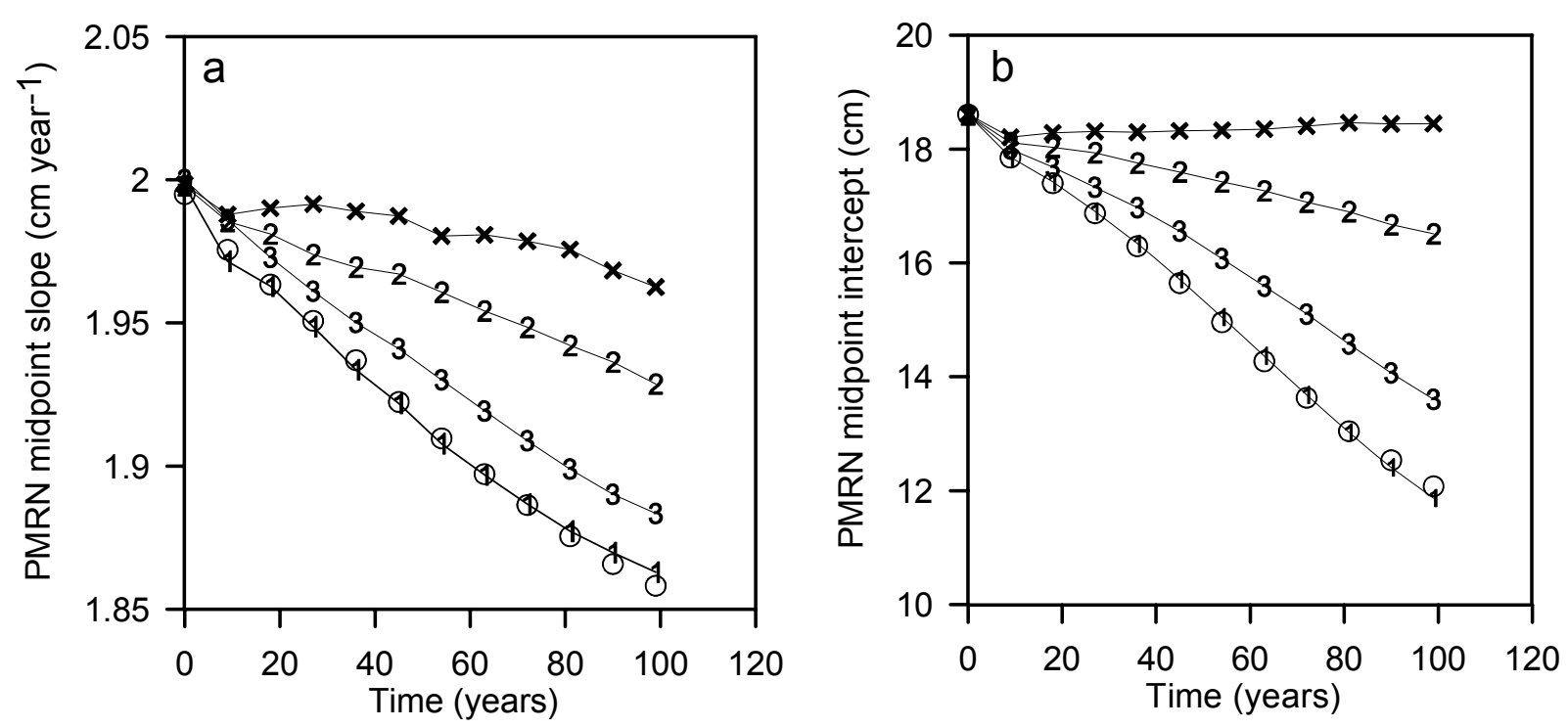
Erin S. Dunlop, Brian J. Shuter, Ulf Dieckmann

\section{Appendix 1. Model parameters and their values}

\begin{tabular}{|c|c|c|c|c|}
\hline Symbol & Description & Equation & Source & Value \\
\hline $\bar{L}$ & Initial mean body size (cm) & - & 1 & 7.71 \\
\hline$L_{s}$ & Initial standard deviation of body size (cm) & - & 1 & 1.43 \\
\hline $\bar{X}$ & Initial mean reaction norm slope $\left(\mathrm{cm}_{\text {year }}{ }^{-1}\right)$ & - & 1 & 2.0 \\
\hline $\bar{Y}$ & Initial mean reaction norm intercept $(\mathrm{cm})$ & - & 1 & 18.6 \\
\hline$W$ & Width of reaction norm $(\mathrm{cm})$ & - & 1 & 13.5 \\
\hline$m_{1-3}$ & Mortality probability for ages 1 to 3 & - & 1 & 0.27 \\
\hline$m_{4+}$ & Mortality probability for ages 4 and older & - & 1 & 0.54 \\
\hline$H_{1}$ & Constant in fecundity function $\left(\mathrm{cm}^{-1}\right)$ & 3 & 3 & 0.64 \\
\hline$H_{2}$ & Constant in fecundity function & 3 & 3 & 3.02 \\
\hline$d$ & Constant in stock-recruitment function & 4 & 2 & 0.89 \\
\hline$A$ & Constant in stock-recruitment function & 4 & 2 & $1.4 \cdot 10^{-4}$ \\
\hline$b$ & Constant in stock-recruitment function & 4 & 2 & $1.9 \cdot 10^{-4}$ \\
\hline$c$ & Constant in stock-recruitment function $\left({ }^{\circ} \mathrm{C}^{-1}\right)$ & 4 & 2 & 0.72 \\
\hline$h_{\max }$ & Maximum immature growth rate $\left(\mathrm{cm}\right.$ year $\left.{ }^{-1}\right)$ & 6 & 1 & 9.12 \\
\hline$q$ & Constant in growth function & 6 & 1 & 0.29 \\
\hline$j$ & Constant in growth function & 6 & 1 & 0.031 \\
\hline$h_{s}$ & Standard deviation of growth rate $\left(\mathrm{cm}\right.$ year $\left.{ }^{-1}\right)$ & - & 1 & 0.91 \\
\hline$g$ & Reproductive investment rate $\left(\right.$ year $\left.^{-1}\right)$ & 8 & 3 & 0.37 \\
\hline$C_{1}$ & Constant in first parental care function & 9 & 2 & 42.9 \\
\hline$C_{2}$ & Constant in first parental care function & 9 & 2 & 0.42 \\
\hline$I_{s}$ & \multicolumn{2}{|c|}{ Constant in second parental care function $\left(\right.$ year $\left.^{-1} \mathrm{~cm}^{-1}\right) \mathrm{A} 3.1$} & 3 & -2.85 \\
\hline$I_{i}$ & Constant in second parental care function $\left(\right.$ year $\left.^{-1}\right)$ & A3.1 & 3 & 11.19 \\
\hline$\tilde{M}_{p, 0}$ & Constant in third parental care function & 12 & - & 0.5 \\
\hline$L_{0}$ & Constant in third parental care function $(\mathrm{cm})$ & 12 & - & 40 \\
\hline
\end{tabular}

Sources: (1) Opeongo Lake creel data reproduced from Shuter et al. (1987), (2) Opeongo Lake creel and spawning data reproduced from Shuter and Ridgway (2002), (3) Opeongo Lake and Provoking Lake data reproduced from Dunlop et al. (2005a, b). 
Erin S. Dunlop, Brian J. Shuter, Ulf Dieckmann

\section{Appendix 2. Sensitivity analyses}

We performed sensitivity analyses on various model parameters and assumptions. We carried out our sensitivity analyses with size-selective mortality applied to individuals larger than $18 \mathrm{~cm}$ and examined the effect of the varied parameters or assumptions on the final position (i.e., in year 100) of the probabilistic maturation reaction norm (PMRN) midpoint. The measure of sensitivity used is therefore the amount of evolution observed in the PMRN over a 100-year period.

(i) Maximum mortality probability in the third parental care mechanism

We varied the $\tilde{M}_{p, 0}$ in Equation (12) between 0.1 and 0.5 to explore the consequences of

the third parental care mechanism. We found that as we increase the mortality rate $\tilde{M}_{p, 0}$ applied to the offspring of small parents, the evolutionary response to size-selective mortality decreases (Table A2.1).

(ii) Minimum size limit in the size-selective mortality regime

We tested the effect of raising the minimum size limit in our size-selective harvesting regime to $20,22,24,26$, and $28 \mathrm{~cm}$. The results of this sensitivity analysis show that raising the minimum size limit between 20 and $22 \mathrm{~cm}$ causes a slight increase in the amount of PMRN evolution, whereas raising the minimum size limit beyond $24 \mathrm{~cm}$ lessens the amount of evolution observed (Table A2.1).

(iii) Combination of age-0 mortality and size-selective mortality

We determined the combined effect of age- 0 mortality of 0.3 and size-selective mortality (on individuals greater than $18 \mathrm{~cm}$ ) of 0.3 ; this causes only a minor decrease in the amount of PMRN evolution compared to a scenario with only 0.3 mortality probability on individuals greater than $18 \mathrm{~cm}$ (Table A2.1). 
Erin S. Dunlop, Brian J. Shuter, Ulf Dieckmann

(iv) Stochasticity in the stock-recruitment relationship

We added normally distributed noise into the stock-recruitment relationship by drawing recruitment numbers randomly from a normal distribution centered on the deterministic number of recruits (from Equation 4) with a standard deviation equal to either $10 \%$ or $20 \%$ of the number of recruits. This noise has little influence on the evolutionary response with a slight tendency to increase the amount of PMRN evolution (Table A2.1).

\section{(v) Deterministic maturation reaction norm}

To test the implications of removing stochasticity from the maturation process, we modeled the response of a deterministic maturation reaction norm to size-selective mortality. Not surprisingly, making the maturation reaction norm deterministic results in a larger evolutionary response (Table A2.1).

\section{(vi) Density-dependent growth}

In our test of the sensitivity of model results to density-dependence, we disregarded the relationship between growth rate and population abundance. Immature growth then differed between individuals and years only stochastically around the mean immature growth rate $\bar{h}_{i}$ of the initial population. The results show that, in the absence of density dependence, the amount of PMRN evolution decreases when the mean immature growth rate is increased (Table A2.1). When the mean immature growth rate is held constant at a slow rate (i.e., at $6 \mathrm{~cm} \mathrm{year}^{-1}$ ), the amount of PMRN evolution observed is larger compared to results with density-dependence; the opposite pattern is observed when the mean immature growth rate is held constant at higher rates (i.e., at and beyond $7 \mathrm{~cm}_{\text {year }}{ }^{-1}$; Table A2.1). 
Erin S. Dunlop, Brian J. Shuter, Ulf Dieckmann

\section{(vii) Background mortality}

We performed a sensitivity analysis on the background level of age-specific mortality applied to older individuals (ages 4+). We did this to ascertain whether the amount of evolution observed in response to size-selective mortality is larger than the effect of the elevated agespecific mortality of older individuals. To do so, we altered the background age-specific annual mortality of older individuals from 0.54 (the original level) to 0.27 in order to make it equal to that of younger individuals, while at the same time applying a size-selective annual mortality of 0.5 to individuals above $18 \mathrm{~cm}$. The results indicate that decreasing the background mortality of older individuals reduces the amount of evolution in response to size-selective harvest: the PMRN midpoint for a 5-year-old decreases by $10.82 \mathrm{~cm}$ with the original background mortality of 0.54 and by $8.36 \mathrm{~cm}$ when the background mortality is reduced to 0.27 . Therefore, the evolutionary response with the reduced background mortality is still substantial and is significantly larger than the difference in response between the two background mortalities. (viii) Coefficients of genetic variation in the initial population

We performed a sensitivity analysis on the initial population's coefficients of genetic variation in the PMRN midpoint slope and intercept. We tested 100 combinations, with both coefficients of variation ranging between $1 \%$ and $10 \%$ in steps of $1 \%$, and observed the effect on model results. We performed this sensitivity analysis using an annual size-selective mortality of 0.5 applied to individuals above $18 \mathrm{~cm}$. As expected, we found that the amount of evolution in the PMRN slope increases with the initial variance of this slope, and the amount of evolution in the PMRN intercept increases with the initial variance of this intercept (Figure A2.1). 
Erin S. Dunlop, Brian J. Shuter, Ulf Dieckmann

Table A2.1. Sensitivity of changing model parameters and assumptions on the final position of the probabilistic maturation reaction norm (PMRN) midpoint slope and intercept after 100 years of annual selective mortality probability.

\begin{tabular}{|c|c|c|c|c|}
\hline Modification made & Targets of & Selective & PMRN & PMRN \\
\hline in sensitivity & selective & mortality & slope & intercept \\
\hline analysis & mortality & probability & $\left(\mathrm{cm} \mathrm{year}^{-1}\right)$ & $(\mathrm{cm})$ \\
\hline Baseline scenario $^{a}$ & $>18 \mathrm{~cm}$ & 0.3 & 1.86 & 12.08 \\
\hline$\tilde{M}_{p, 0}=0.1$ & $>18 \mathrm{~cm}$ & 0.3 & 1.87 & 12.30 \\
\hline$\tilde{M}_{p, 0}=0.2$ & $>18 \mathrm{~cm}$ & 0.3 & 1.87 & 12.32 \\
\hline$\tilde{M}_{p, 0}=0.3$ & $>18 \mathrm{~cm}$ & 0.3 & 1.87 & 12.86 \\
\hline$\tilde{M}_{p, 0}=0.4$ & $>18 \mathrm{~cm}$ & 0.3 & 1.88 & 13.30 \\
\hline$\tilde{M}_{p, 0}=0.5$ & $>18 \mathrm{~cm}$ & 0.3 & 1.88 & 13.60 \\
\hline Minimum size limit & $>20 \mathrm{~cm}$ & 0.3 & 1.85 & 12.13 \\
\hline Minimum size limit & $>22 \mathrm{~cm}$ & 0.3 & 1.84 & 11.86 \\
\hline Minimum size limit & $>24 \mathrm{~cm}$ & 0.3 & 1.82 & 12.13 \\
\hline Minimum size limit & $>26 \mathrm{~cm}$ & 0.3 & 1.84 & 12.72 \\
\hline Minimum size limit & $>28 \mathrm{~cm}$ & 0.3 & 1.84 & 13.37 \\
\hline Age- 0 and size-selective & age- $0 \&>18 \mathrm{~cm}$ & $0.3+0.3$ & 1.88 & 13.05 \\
\hline $10 \%$ stochasticity in $\mathrm{SR}^{\mathrm{b}}$ & $>18 \mathrm{~cm}$ & 0.3 & 1.84 & 12.00 \\
\hline $20 \%$ stochasticity in $\mathrm{SR}^{\mathrm{b}}$ & $>18 \mathrm{~cm}$ & 0.3 & 1.86 & 11.86 \\
\hline Deterministic $\mathrm{MRN}^{\mathrm{c}}$ & $>18 \mathrm{~cm}$ & 0.3 & 1.85 & 10.05 \\
\hline Constant mean growth ${ }^{\mathrm{d}}=6 \mathrm{~cm}$ year $^{-1}$ & $>18 \mathrm{~cm}$ & 0.3 & 1.84 & 11.58 \\
\hline
\end{tabular}


Erin S. Dunlop, Brian J. Shuter, Ulf Dieckmann

\begin{tabular}{llccc} 
Constant mean growth $^{\mathrm{d}}=7 \mathrm{~cm} \mathrm{year}^{-1}$ & $>18 \mathrm{~cm}$ & 0.3 & 1.87 & 14.17 \\
Constant mean growth $^{\mathrm{d}}=8 \mathrm{~cm} \mathrm{year}^{-1}$ & $>18 \mathrm{~cm}$ & 0.3 & 1.94 & 16.73 \\
Constant mean growth $^{\mathrm{d}}=9.12^{\mathrm{e}} \mathrm{cm} \mathrm{year}^{-1}>18 \mathrm{~cm}$ & 0.3 & 1.98 & 18.10 \\
Constant mean growth $^{\mathrm{d}}=10 \mathrm{~cm} \mathrm{year}^{-1}$ & $>18 \mathrm{~cm}$ & 0.3 & 1.99 & 18.69 \\
\hline
\end{tabular}

${ }^{a}$ The baseline scenario is included for comparison; it is given by the standard results (i.e., without any of the modifications considered in the sensitivity analyses) for 100 years of selective mortality probability of 0.3 on individuals above $18 \mathrm{~cm}$.

${ }^{\mathrm{b}} \mathrm{SR}=$ stock-recruitment relationship (Equation 4).

${ }^{\mathrm{c}}$ The slope and intercept represent a deterministic maturation reaction norm with vanishing envelope width.

${ }^{\mathrm{d}}$ Density-dependent growth disregarded here

${ }^{\mathrm{e}}$ Note that $\overline{h_{i}}=h_{\max }=9.12 \mathrm{~cm}$ follows from Equation (6) for $D=0$ 
Erin S. Dunlop, Brian J. Shuter, Ulf Dieckmann

\section{Figure captions}

Figure A2.1. Influence of different initial combinations of coefficients of variation on the evolutionary response to 100 years of fishing in (a) probabilistic maturation reaction norm (PMRN) midpoint slope and (b) PMRN midpoint intercept, measured by the absolute difference between initial (year 1) and final (year 100) slope or intercept. Results are averaged over 50 independent model runs. Annual size-selective mortality probability was 0.5 for individuals larger than $18 \mathrm{~cm}$. 
Erin S. Dunlop, Brian J. Shuter, Ulf Dieckmann

Figure A2.1
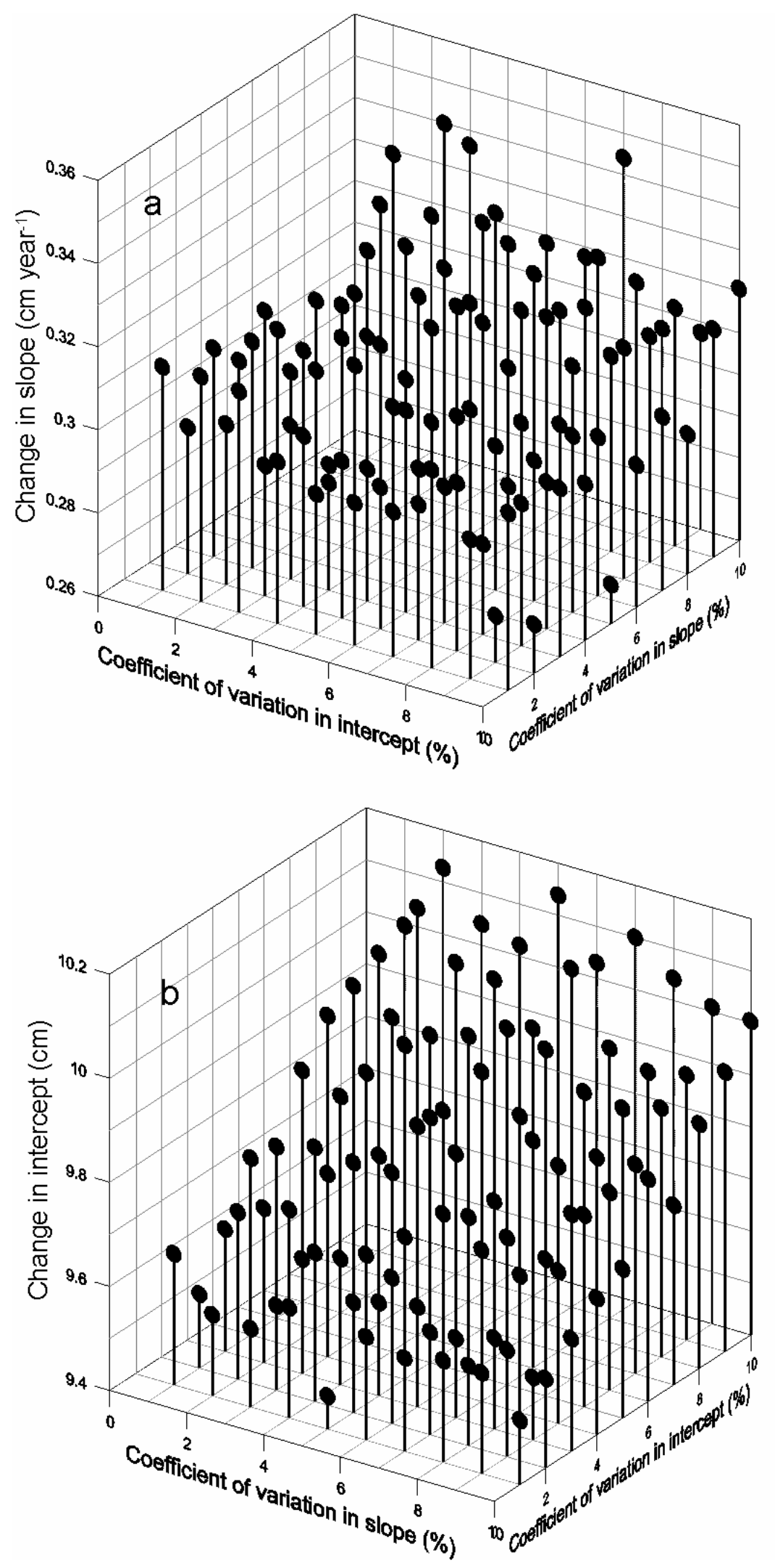
Erin S. Dunlop, Brian J. Shuter, Ulf Dieckmann

\section{Appendix 3. Estimation of size-dependent parental mortality}

From 1997 to 2003, all of the nesting males in Jones Bay (perimeter $=5 \mathrm{~km}$ ) of Opeongo Lake were captured with fishing rods, had their body sizes measured, had 3-6 scales removed for aging purposes, were tagged with internal passive integrated transponder tags (Biomark, Boise Idaho) and external t-bar tags (Halprint, Australia), and were released back onto their nests within 5 minutes (Ridgway et al. 1991). Smallmouth bass show extremely high nest-site fidelity, as males that nest in multiple years tend to return to within close proximity of their original nest site; in the Opeongo Lake population, 94\% of previously nesting males return to within $200 \mathrm{~m}$ and $35 \%$ return to within $20 \mathrm{~m}$ (the modal distance category) of their original nest site (Ridgway et al. 2002). Therefore, by sampling all nesting males in Jones Bay in multiple years, it was possible to identify which male parents did not return to nest in a subsequent year. Under the reasonable assumptions that the number of males straying outside of the sampling area was negligible and that those that did not return had suffered mortality, the size-dependent annual mortality probability was estimated by dividing, separately for each size class, the number of males that did not return to nest in a subsequent year by the total number of males that were tagged (following an approach similar to that developed in Dunlop et al. 2005b). These annual mortality probabilities of reproducing individuals $M_{r, L}$ were converted to instantaneous mortality rates $I_{r, L}$, and regressed on body size $L, I_{r, L}=I_{s} L+I_{i}$ (Figure 1f shows this relationship in terms of annual mortality probabilities). We then assumed that the background annual mortality probability of 0.54 experienced by older fish was the annual mortality probability $M_{b}$ of nonreproducing individuals. The increase in annual mortality probability induced by reproduction for a parent of body size $L$ is thus given by

$$
M_{p, L}=M_{b}-M_{r, L}
$$

